\title{
Infrared spectra of pyroxenes (crystalline chain silicates) at room temperature
}

\author{
J. E. Bowey ${ }^{\circledR},{ }^{1 \star}$ A. M. Hofmeister ${ }^{2 \star}$ and E. Keppel ${ }^{2}$ \\ ${ }^{1}$ School of Physics and Astronomy, Cardiff University, Queen's Buildings, The Parade, Cardiff, Wales CF24 3AA, UK \\ ${ }^{2}$ Department of Earth and Planetary Sciences, Washington University, 1 Brookings Drive, St. Louis, MO 63130, USA
}

Accepted 2020 July 27. Received 2020 July 24; in original form 2020 March 25

\begin{abstract}
Crystals of pyroxene are common in meteorites but few compositions have been recognized in astronomical environments due to the limited chemistries included in laboratory studies. We present quantitative room-temperature spectra of $17 \mathrm{Mg}-, \mathrm{Fe}-$, and Ca-bearing ortho- and clinopyroxenes, and a Ca-pyroxenoid in order to discern trends indicative of crystal structure and a wide range of composition. Data are produced using a diamond anvil cell: our band strengths are up to six times higher than those measured in $\mathrm{KBr}$ or polyethylene dispersions, which include variations in path length (from grain size) and surface reflections that are not addressed in data processing. Pyroxenes have varied spectra: only two bands, at 10.22 and $15.34 \mu \mathrm{m}$ in enstatite $\left(\mathrm{En}_{99}\right)$, are common to all. Peak wavelengths generally increase as $\mathrm{Mg}$ is replaced by Ca or Fe. However, two bands in $\mathrm{MgFe}$-pyroxenes shift to shorter wavelengths as the Fe component increases from 0 to 60 per cent. A high-intensity band shifts from 11.6 to $11.2 \mu \mathrm{m}$ and remains at $11.2 \mu \mathrm{m}$ as Fe increases to 100 per cent; it resembles an astronomical feature normally identified with olivine or forsterite. The distinctive pyroxene bands between 13 and $16 \mu \mathrm{m}$ show promise for their identification in Mid-Infrared-Instrument spectra obtained with the James Webb Space Telescope. The many pyroxene bands between 40 and $80 \mu \mathrm{m}$ could be diagnositic of silicate mineralogy if data were obtained with the proposed Space Infrared Telescope for Cosmology and Astrophysics. Our data indicate that comparison between room-temperature laboratory bands for enstatite and cold $\sim 10-K$ astronomical dust features at wavelengths $\gtrsim 28 \mu \mathrm{m}$ can result in the identification of (Mg,Fe)- pyroxenes that contain 7-15 per cent less $\mathrm{Fe}$ - than their true values because some temperature shifts mimic some compositional shifts. Therefore some astronomical silicates may contain more $\mathrm{Fe}$, and less $\mathrm{Mg}$, than previously thought.
\end{abstract}

Key words: solid state: refractory-methods: laboratory: solid state-techniques: spectroscopic-protoplanetary discscircumstellar matter - infrared: general.

\section{INTRODUCTION}

Silicate dust is ubiquitous in galaxies; before the mid-1990s amorphous, or glassy, submicrometre-sized silicate grains were assigned as carriers of broad strong absorption and emission bands centred at 10 and $18 \mu \mathrm{m}$ in dusty environments including the envelopes of evolved stars, the interstellar medium (ISM) and comets. Later small fractions of crystalline silicates were tentatively identified in oxygenrich circumstellar environments (Waters et al. 1996) and firmly identified in comets (Wooden et al. 1999) and young stellar objects (YSOs, Malfait et al. 1998) in far-infrared (far-IR) spectra obtained by ESA's Infrared Space Observatory satellite. More recently, Spitzer Infrared Spectrograph (IRS) spectra have revealed crystalline silicate absorption bands in ultraluminous IR galaxies (Spoon et al. 2006) and OH-megamasing galaxies (Willett et al. 2011). A systematic search of 7.5-38 $\mu \mathrm{m}$ Spitzer spectra for crystalline silicates finds that 868 spectra of 790 sources including early-type stars, evolved stars and galaxies contain crystalline silicates (Chen et al. 2016); spectra show evidence of olivine (forsterite), pyroxene (enstatite),

^E-mail: boweyj@cardiff.ac.uk (JEW); hofmeist@levee.wustl.edu (AMH) or other unidentified crystalline minerals. However, many of these identifications are tentative because relatively few minerals have been compared with astronomical spectra despite the wide variety of crystalline silicates found in meteorites and on Earth (see e.g. Bowey \& Adamson 2002, for a fuller discussion). Astronomical grains are mostly expected to be magnesium-rich; whilst this is likely, laboratory data for magnesium-poor chemical compositions are limited to one or two compositions (e.g. Tamanai, Mutschke \& Blum 2009) and the spectra not readily available, so alternatives have not been much explored by astrophysicists. Bowey \& Adamson took a different approach, and matched relatively smooth astronomical $10 \mu \mathrm{m}$ profiles with a mixture of crystalline silicates with a relatively small component of amorphous silicate. By this analysis, the enhanced breadth of the $10-\mu \mathrm{m}$ features in the circumstellar discs surrounding young stars and in molecular clouds could be reproduced by a mixture of crystalline pyroxenes with varying stoichiometries ( 80 per cent by mass) and amorphous silicates ( 20 per cent) but the laboratory data and ground-based data were of insufficiently high quality to rigorously test this hypothesis. Recently, Do-Duy et al. (2020) have proposed that the enhanced breadth of the $10 \mu \mathrm{m}$ feature in molecular clouds and YSOs is due the presence of a few percent of crystalline silicate dust (forsterite). The potential of mixtures of 
other crystalline silicate groups contributing has not been considered recently, even though the meteoritic record indicates a wide variety of crystalline silicates are present in at least some of these environments. Pyroxenes are a likely candidate because they are amongst the most common silicates in the most primitive meteorites.

\subsection{Laboratory studies}

Transmission spectra of pyroxenes embedded in $\mathrm{KBr}$ or polyethylene pellets have been previously published by Ferraro (1982), Jäger et al. (1998), and Chihara et al. (2002) but laboratory studies in the astronomical literature contain a relatively limited range of compositions including magnesium and iron: $4 \mathrm{Mg}$-rich $\mathrm{Mg}-\mathrm{Fe}-$ pyroxenes (Jäger et al. 1998), $7 \mathrm{Mg}$-rich and $1 \mathrm{Fe}$-pyroxene (Chihara et al. 2002). Microspectroscopic and chemical techniques have been used to obtain $8-17-\mu \mathrm{m}$ spectra of individual meteoritic grains, covering the Mg-rich end of the series (Bowey et al. 2007). We present new spectra of $8 \mathrm{Mg}$ - and Fe-bearing orthopyroxenes, $9 \mathrm{Mg}$-, $\mathrm{Ca}$-, and $\mathrm{Fe}$-bearing clinopyroxenes, and one $\mathrm{Ca}$-bearing pyroxenoid obtained at room temperature over the wavelength range of the fundamental IR bands for the range of chemistries extant in these solid-solution series.

Data were collected from powdered samples compressed in a diamond anvil cell (DAC) in order to form thin films of uniform thickness with minimal spaces between the grains (no embedding medium is used). Compressing the powder reduces the effect of scattering because the reflection at grain boundaries is minimized. Grain sizes are deduced experimentally, to give the sharpest and most repeatable IR bands (Hofmeister, Keppel \& Speck 2003). Excess pressure is released prior to measuring the spectra so that the cell acts only as a sample-holder (see Hofmeister et al. and references therein for the detailed methodology). The method produces nearly perfect absorption spectra similar to those derived from the reflectivity of single crystals, with only slight rounding of the strongest peaks.

Our wavelength-absorption coefficients can be used as an optical depth profile and directly compared with astronomical observations of optically thin emission, and foreground absorption in the IR in order to derive the chemical and temperature properties of the dust ${ }^{1}$ once these factors are better constrained reflectivity studies of a narrower range of species can be used to deduce grain sizes and shapes from weak spectral peaks. Room-temperature DAC spectra are available for olivines (Pitman et al. 2010), hydrosilicates (Hofmeister \& Bowey 2006), silicate overtones (Bowey \& Hofmeister 2005), and glasses (Speck, Wittington \& Hofmeister 2011).

To encourage consistent nomenclature between the disciplines of mineralogy, astrophysics, and chemistry, we describe the mineralogical nomenclature of pyroxenes in Section 2; the samples, experimental and data processing details are in Section 3 where we also discuss the DAC technique and present a method for estimating absorption coefficients from thin films of compressed powder. The complete spectra are presented in frequency units in Section 4, and detailed compositional-wavelength shifts are discussed and quantified in Section 5. The new data are compared with published

\footnotetext{
${ }^{1}$ An alternative method is to use absorption coefficients from indices of refraction, however, IR spectra of strong spectral features calculated from refractive indices are often wavelength shifted in relation to those of the laboratory spectra of particulates (e.g. Bohren \& Huffman 1983; Jäger et al. 1998; Sogawa et al. 2006). Problems with particulate data have been resolved, or shown to be due to misunderstandings of mineralogy and problems with the laboratory technique (Speck, Hofmeister \& Barlow 1999; Bowey, Adamson \& Speck 2000; Hofmeister et al. 2003; Imai et al. 2009).
}

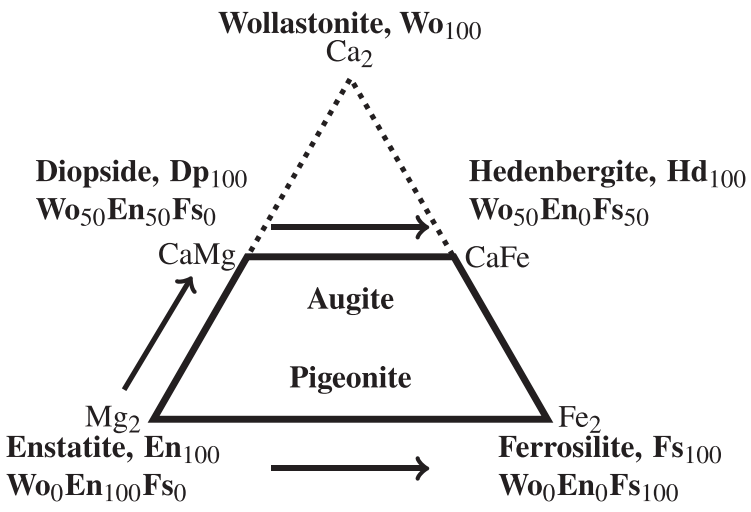

Figure 1. Nomenclature and metal components of pyroxenes, chain silicates of formula $[\mathrm{Metal}]_{2}-\mathrm{Si}_{2} \mathrm{O}_{6}$ : solid-solution series studied in this paper are enstatite-ferrosilite (En-Fs orthopyroxenes), and monoclinic pyroxenes in the enstatite-diopside (En-Dp) and diopside-hedenbergite (Dp-Hd) series; pigeonite and augite have intermediate $\mathrm{Mg} / \mathrm{Fe}$ ratios with increasing $\mathrm{Ca}$ content. Wollastonite is a pyroxenoid.

room- and low-temperature particulate spectra in Section 7. The data and initial astronomical implications are summarized in Section 8.

\section{PYROXENES}

Pyroxenes are chain silicates, characterized by chains of $\mathrm{SiO}_{4}$ tetrahedra which are linked along the crystallographic $c$-axis by shared oxygen atoms. The generic formula is $(\mathrm{M} 2, \mathrm{M} 1) \mathrm{T}_{2} \mathrm{O}_{6}$ where $\mathrm{M} 2$ refers to cations in a distorted octahedral coordination, M1 to cations in a regular octahedral coordination and $\mathrm{T}$ to tetrahedrally coordinated cations (usually $\mathrm{Si}^{4}$ ) (Morimoto et al. 1988). The triangle in Fig. 1 illustrates the nomenclature of chain silicates in the pyroxene and pyroxenoid groups, with the most common substitutions. Minerals in the quadrilateral at the bottom of the figure are denoted pyroxenes. In pyroxenes $\mathrm{Mg}^{2+}, \mathrm{Fe}^{2+}$ occupy M1 and M2 lattice sites whilst $\mathrm{Ca}^{2+}$ occupies only M2 sites. Pyroxenoids occur when $\mathrm{Ca}^{2}+$ occupies both $\mathrm{M} 1$ and $\mathrm{M} 2$ sites (i.e. $\mathrm{Ca}^{2+}$ occupancy of $\mathrm{M} 1+\mathrm{M} 2>50$ per cent), and the chains are twisted with a repeat of 3 or more. Pyroxenoids are represented here by the $\mathrm{Ca}$ end-member, wollastonite $\left(\mathrm{Ca}_{2} \mathrm{Si}_{2} \mathrm{O}_{6}\right.$, $\mathrm{Wo}_{100}$ ). Mineralogical formulae $\mathrm{Wo}_{w} \mathrm{En}_{x} \mathrm{Fs}_{y}$ are calculated from the atomic per cent of each of $\mathrm{Ca}^{2+}, \mathrm{En}^{2+}$, and $\mathrm{Fe}^{2+}$, respectively; if no other elements were included $w+x+y \simeq 100$.

We obtain spectra from samples listed in Table 1 representing three sides of the pyroxene quadrilateral because these minerals are abundant in terrestrial environments and in meteorites. Minerals are named according to the percentage of wollastonite and enstatite in the unit cell; the ferrosilite content can be deduced by subtraction or, more accurately, from the chemical formulae listed in the table.

(i) The enstatite $\left(\mathrm{Mg}_{2} \mathrm{Si}_{2} \mathrm{O}_{6}, \mathrm{En}_{100}\right)$-ferrosilite $\left(\mathrm{Fe}_{2} \mathrm{Si}_{2} \mathrm{O}_{6}, \mathrm{Fs}_{100}\right)$ series where $\mathrm{Mg}^{2+}$ is replaced by $\mathrm{Fe}^{2+}$. In this orthopyroxene series the crystal axes are orthogonal to each other because $\mathrm{Fe}^{2+}$ and $\mathrm{Mg}^{2+}$ are of similar size. However, in circumstances of rapid crystallization, one axis can be inclined giving rise to a clinoenstatite to clinoferrosilite series with similar compositions, but because these are rare in terrestrial samples they are beyond the scope of this paper. Chihara et al. found little difference between the infrared spectra of orthoenstatite and clinoenstatite at wavelengths shorter than $40 \mu \mathrm{m}$ and significant differences at longer wavelengths (see Section 6.2).

(ii) The enstatite-diopside-wollastonite $\left(\mathrm{Ca}_{2} \mathrm{Si}_{2} \mathrm{O}_{6} ; \mathrm{Wo}_{100}\right)$ clinopyroxene series where $\mathrm{Mg}^{2+}$ in the M2 site are replaced by larger $\mathrm{Ca}^{2}+$ cations. Pyroxenes comprise silicates with $\leq 50$ per cent 
Table 1. Sample descriptions of the 18 minerals studied. For the natural samples, the chemical formulae are computed from electron microprobe analyses obtained from similar samples at the same locality, the formulation of the synthetics is described in the references. Mass density, $\rho$, is required for the derivation of mass extinction coefficients (see Section 3.3, equation 2) from the measured natural log absorption coefficients described in Section 3.2, equation (3).

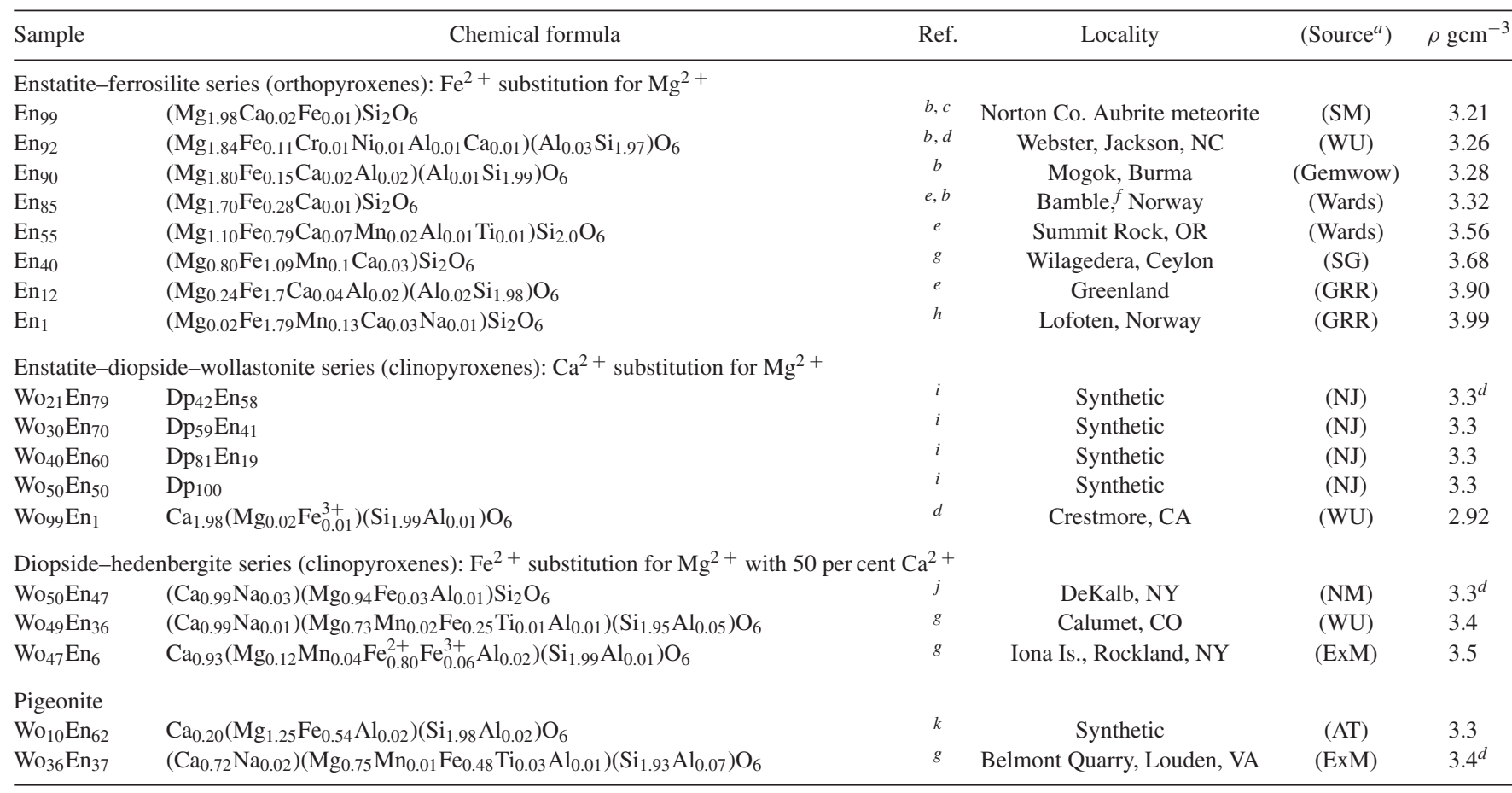

Notes: ${ }^{a} \mathrm{NJ}=\mathrm{N}$. Johnson; $\mathrm{NM}=$ National Museum of Natural History sample \#R18682;ExM = Excalibur Mineral Co.; AT = Alan Turnock; WU = Washington University; $\mathrm{SM}=$ Schooler's Minerals; RFD = R. F. Dymek sample \#72816; SG = S. Guggenheim; GRR = G. R. Rossman.

${ }^{b}$ See Hofmeister (2012) for microprobe analyses: The aubrite contains 5 per cent microscopic diopside inclusions (blebs) of composition $\left.\mathrm{Mg}_{1.10} \mathrm{Ca}_{0.85} \mathrm{Na}_{0.02} \mathrm{Al}_{0.02}\right) \mathrm{Si}_{2} \mathrm{O}_{6} \equiv \mathrm{Wo}_{43} \mathrm{En}_{55}$. The Mogok sample is a large, gem-quality single-crystal. Near-IR spectra of the O-H stretching bands and visible to ultraviolet spectra of the electronic transitions (e.g. Fe2 +) are also provided of these materials.

${ }^{c}$ Okada et al. (1988).

${ }^{d}$ Deer, Howie \& Zussman (1978); clinopyroxene and pigeonite mass densities, $\rho$ are from tabulated values and are quoted to 3 significant figures if they are from the same locality, or to two significant figures if they are estimates based on a similar composition.

${ }^{e}$ Goldman \& Rossman (1979).

${ }^{f}$ This is the sample incorrectly called 'Bramble’ Enstatite in Bowey et al. (2001).

${ }^{g}$ Microprobe analysis performed at Washington University; analysis in Table A2.

${ }^{h}$ Sample number 433 (Ormaasen 1977).

${ }^{i} \mathrm{Dp}_{59} \mathrm{En}_{41}$ by decomposition of natural tremolite (Johnson \& Fegley 2003), others with similar methodology but different starting compositions (Johnson 2002) and personal communication.

${ }^{j}$ Hemingway et al. (1998); Hofmeister \& Pertermann (2008).

${ }^{k}$ A. Turnock (personal communication); Huebner \& Turnock (1980).

$\mathrm{Ca}^{2+}$, thus diopside $\left(\mathrm{CaMgSi}_{2} \mathrm{O}_{6} ; \mathrm{Wo}_{50} \mathrm{En}_{50}\right.$, or $\left.\mathrm{Dp}_{100}\right)$ is the endmember pyroxene; wollastonite, the end-member pyroxenoid is also included in this study because it appears in meteorites. The larger radius of $\mathrm{Ca}^{2+}$ changes the shape of the unit cell producing crystals with an inclined $a$-axis, giving rise to a monoclinic structure (clinopyroxenes).

(iii) The diopside-hedenbergite $\left(\mathrm{CaFeSi}_{2} \mathrm{O}_{6} ; \mathrm{Wo}_{50} \mathrm{En}_{0}\right)$ clinopyroxene series where $\mathrm{Fe}^{2+}$ replaces $\mathrm{Mg}^{2+}$ in the M1 site; these crystals are also monoclinic.

Two pigeonites, whose composition does not fall on the edges of the pyroxene quadrilateral, are also included to indicate some of the variety of terrestrial pyroxenes. Pigeonites are monoclinic pyroxenes with a relatively-low calcium content.

\subsection{Effect of trace elements and impurities in natural samples}

Natural samples tend to contain trace quantities of $\mathrm{Cr}, \mathrm{Ni}, \mathrm{Mn}, \mathrm{Ti}$, and $\mathrm{Na}$ which replace $\lesssim 5$ percent of the main constituents of the silicates. Although different cations theoretically affect the spectra, they do not normally do so at this level of substitution unless the impurity has a substantially different mass, charge or volume from the cation it replaces. By convention traces of $\mathrm{Mn}^{2+}$ and $\mathrm{Ni}^{2+}$ are summed with $\mathrm{Fe}^{2+}$, because the cations are of similar size and are indistinguishable from $\mathrm{Fe}^{2+}$ in IR spectra. Additional samples were measured that have chemical compositions only slightly different from those reported here, and their spectra were nearly identical.

Impurities appear as weak bands in regions that are transparent for the major composition. We found quartz impurities in our original $\mathrm{En}_{1}$ and $\mathrm{En}_{12}$ spectra and subtracted them from our data (Appendix A1). Sample $\mathrm{En}_{99}$ is a good test case for less easily distinguishable impurities because the meteoritic sample is known to contain 5 per cent of microscopic clinopyroxene inclusions (see Section 6.1), which is the canonical detectable limit. At higher $\gtrsim 10$ per cent concentrations impurities can also broaden bands and cause them to blend, the effect of substantial substitution of $\mathrm{Al}^{3+}$ for $\mathrm{Si}^{4+}$ will be explored in a later paper. Here, we report data on 
samples with the smallest quantities of minor impurities to focus on effects of the major cation variations $(\mathrm{Mg}, \mathrm{Fe}$, and $\mathrm{Ca}$ ) and we have found no evidence that impurities significantly affect the current data set.

\section{EXPERIMENTAL METHODS}

Samples are described in Table 1. The chemical formulae were computed from published chemical analysis of samples from the same locality, as cited, or from electron microprobe analysis performed at Washington University using a JEOL-733 equipped with Advance Microbeam automation. The accelerating voltage was $15 \mathrm{kV}$, beam current was $30 \mathrm{nA}$, and beam diameter was $1 \mu \mathrm{m}$. X-ray matrix corrections were based on a modified Armstrong (1988) CITZAF routine. Silicates and oxides were used as primary standards.

IR absorption spectra were acquired using an evacuated Bomem DA 3.02 Fourier transform spectrometer with an accuracy of $\sim 0.01 \mathrm{~cm}^{-1}$. An $\mathrm{SiC}$ source was used for the entire spectral range. The number of scans ranged from 500 to 2000 . Far-IR spectra, from $\sim 50$ to $650 \mathrm{~cm}^{-1}(\sim 200-15 \mu \mathrm{m})$, were obtained at 1-2 $\mathrm{cm}^{-1}$ resolution with an Si-bolometer and, in some cases a $12 \mu \mathrm{m}$ coated mylar beam splitter was used to provide higher throughput at the lowest frequencies. Mid-IR spectra from $\sim 450$ to $4000 \mathrm{~cm}^{-1}(\sim 23-$ $2.5 \mu \mathrm{m})$ were obtained with a $\mathrm{HgCdTe}$ detector and a $\mathrm{KBr}$ beam splitter and $1-2-\mathrm{cm}^{-1}$ resolution.

Samples were hand-ground for a maximum of 10 minutes in order to reduce the effects of crystal orientation without degrading the longrange crystal structure (see e.g. the study by Imai et al. 2009, for the spectroscopic effect of excessive mechanical grinding). However, pyroxenes tend to form elongated laths with the long axis parallel to their $c$-axes (the axes of the chains) and these tend to lie on their sides when compressed, the crystal orientation in the DAC will not be perfectly randomized. This effect will be offset slightly by the non-parallel condensing beam of the DAC, so that all the crystal axes are sampled.

Optically-thin, $\sim 0.2$ to $2 \mu \mathrm{m}$-thick, films were made by compressing powders in a DAC to form a uniform thickness by repeatedly applying $\sim 10 \mathrm{kbar}$ pressure for a few seconds. Excess pressure is released prior to measuring the spectra so that the cell acts as a sample holder (Hofmeister et al.) and the crystals revert to their decompressed state by elastic decompression (see Hofmeister et al. 1989 , for decompression after applying hydrostatic pressures of up to $\lesssim 425 \mathrm{kbar}$ in olivine). Various powder thicknesses were used to confirm the existence of weak peaks, to ascertain that optically thin conditions hold for the most intense peaks, and to minimize fringing in the transparent regions (Hofmeister \& Bowey 2006).

Band strengths near $700 \mathrm{~cm}^{-1}$ were calibrated against a film whose thickness was determined by using a $1.93 \mu \mathrm{m}$-thick microphone foil as a spacer around an aperture containing a sample which had been finely ground under alcohol.

Aluminium microphone foils, nominally $2.5 \pm 0.5$ - and $4 \mu \mathrm{m}-$ thick, were purchased on ebay from Geisnote. Their thickness was checked by placing a strip of the thicker foil between two 25-mmdiameter $\mathrm{KBr}$ discs. The absorption spectra showed fringes whose thickness is given by $B=1 /(2 n \Delta v)$, where $\Delta v$ is the average spacing and $n$ is the index of refraction $=1$ for the air gap (Griffiths \& de Haseth 1986). The nominally $4-\mu \mathrm{m}$ foil, was found to be $5.3 \mu \mathrm{m}$ thick. The thin single foil was below $2 \mu \mathrm{m}$ thick because no fringes were seen. In order to move the interference into the measurable near-mid-IR wavelength range, the thinner foil was doubled and the double-thickness measured to be $3.86 \mu \mathrm{m}$ thick.
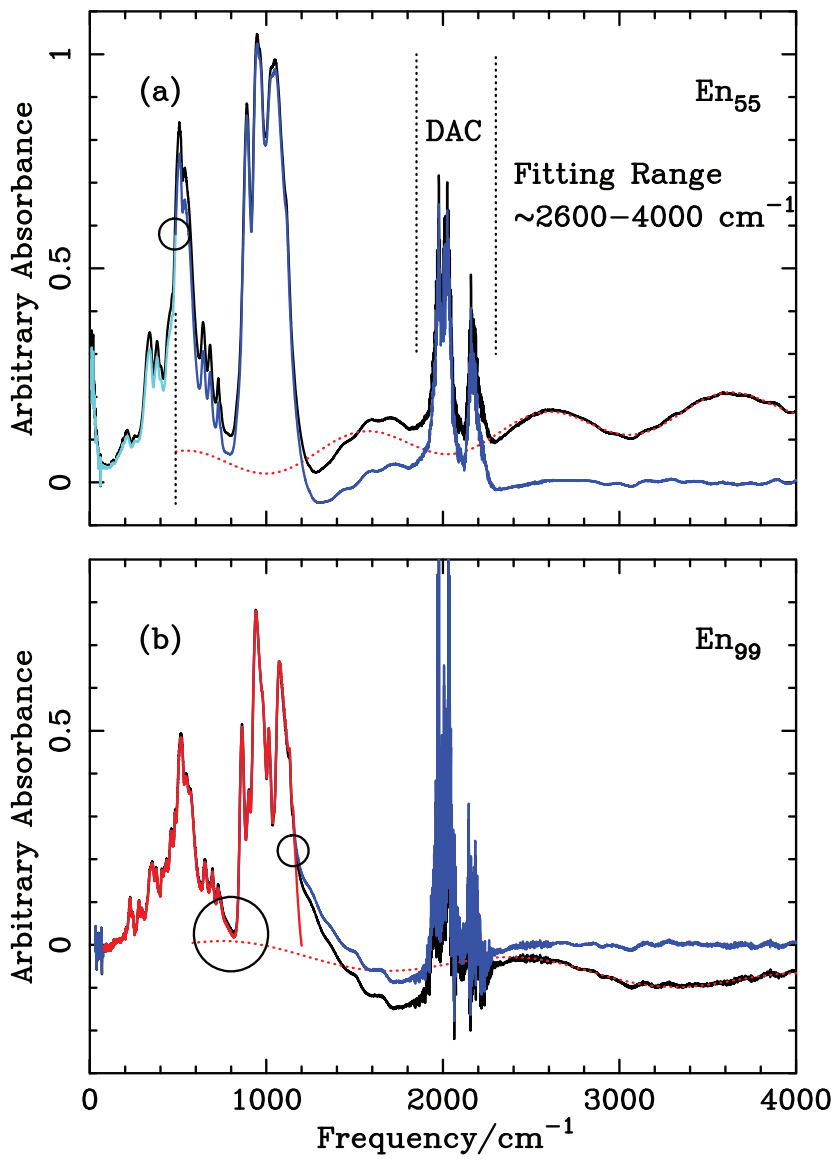

Figure 2. (a) The complete spectrum of $\mathrm{En}_{55}$ before defringing (black) with sinusoidal function fitted to $2600-4000 \mathrm{~cm}^{-1}$ range (red dotted). This was subtracted as far as the merging point near $580 \mathrm{~cm}^{-1}$ to produce the defringed spectrum. The low-frequency region (cyan) was obtained by scaling a spectrum of another film to match the higher frequency spectrum. DAC denotes the region dominated by absorption within the diamond anvil cell. (b) Removing the wing near $1100 \mathrm{~cm}^{-1}$ : black - original spectrum, blue - after defringing, and red - after merging near $1100 \mathrm{~cm}^{-1}$. Small circles indicate the merging points and the large circle highlights the transparent region whose level may be affected by unresolved weak peaks.

\subsection{Data processing}

The $450-4000-\mathrm{cm}^{-1}$ spectra contained underlying fringes which were removed by fitting and subtracting a sloping sinusoidal function to the base line at frequencies higher than $2600 \mathrm{~cm}^{-1}$ (Fig. 2a). Assuming that the absorbance is zero near zero frequency, the average level of the relatively noisy $80-120-\mathrm{cm}^{-1}$ range was subtracted from the far-IR $\left(50-650 \mathrm{~cm}^{-1}\right)$ spectra and then these were scaled to match the defringed mid-IR data.

The apparent broadening (or wing) of the $\gtrsim 1100-\mathrm{cm}^{-1}(9.1-\mu \mathrm{m})$ region in some samples (Fig. 2b) is not due to absorption. The wing is due to strong reflection at frequencies above the strongest Si-O stretching (LO) mode (see Wooten 1972), which reduces the measured transmission, while enhancing the perceived absorption. If the sample were negligibly thin, the wing would not exist. This effect is reduced in films in comparison with the spectra of dispersions, but is not completely absent because the films are slightly wedged. The wing was removed by scaling an exponential function modelled on the same, unaffected, region in $\mathrm{En}_{55}$ to the spectra affected and merging it with the good data at lower frequencies (Fig. 2b). Spectra were subsequently trimmed to cover the region between 


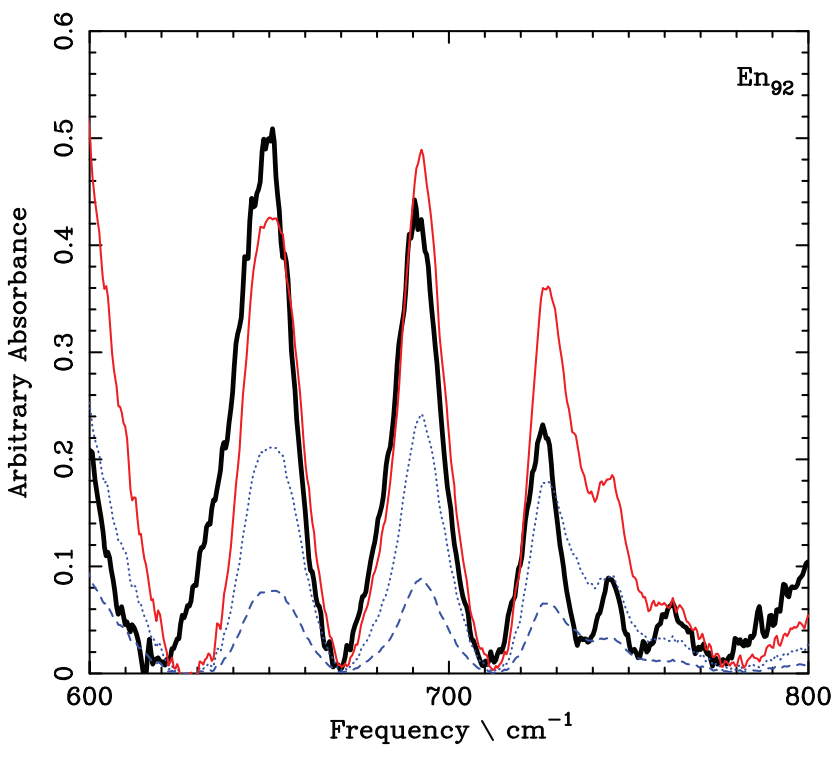

Figure 3. Calibrating the absorbance of En 92 . Film of known thickness (thick black curve), uncalibrated En92 (blue dashed), En 92 matched to $>725 \mathrm{~cm}^{-1}$ bands (blue dotted), preferred match to $<625 \mathrm{~cm}^{-1}$ peaks (solid red).

80 and $1200 \mathrm{~cm}^{-1}(125-8.3 \mu \mathrm{m})$ and normalized to the area under $\mathrm{En}_{55}$ between 80 and $1200 \mathrm{~cm}^{-1}$ since the area under the spectrum is proportional to the number of molecular bonds responsible for the absorption features and that this should be the same for all the pyroxenes. These are the normalized laboratory absorbance spectra $[\bar{a}$, calculated from $a$ in equation (1) below] used to determine the compositional dependence of the peak positions.

Uncertainties in the spectral shapes are more significant at the merging points near $500 \mathrm{~cm}^{-1}(20 \mu \mathrm{m})$, and there is remaining uncertainty in the intrinsic level of the baseline of the transparent regions near $80,600-800$, and $1200 \mathrm{~cm}^{-1}$. Additional measurements of the 600-800 $\mathrm{cm}^{-1}$ region of $\mathrm{En}_{92}$ for band strength calibration (Fig. 3), indicate that there may be unresolved weak peaks near $800 \mathrm{~cm}^{-1}$ in some of the spectra which manifest as a change from a U-shape to a V-shape (e.g. in $E_{99}$ and $E_{92}$ ); they may also be due to the the trace quantities of other cations listed in Table 1.

\subsection{Band-strength calibration}

Laboratory absorbance

$a=-\log _{10} \frac{I_{t}}{I_{*}}=A \times d$,

where $I_{t}$ is the intensity of the beam transmitted through the DAC containing the sample and $I_{*}$ is the intensity of the beam transmitted through the empty cell. $a$ is equivalent to the absorption coefficient, $A$, times the film thickness $d$ in the spectroscopic, chemical, and mineralogical literature. However, astronomers use a natural log absorption coefficient (or optical depth, $\tau$ ) units so our pyroxene data are presented as

$\tau\left(\mu \mathrm{m}^{-1}\right)=\frac{A}{d} \times 2.3026$,

where the factor of 2.3026 is derived from the change of base formula.

Band strengths for the En-Fs series were estimated by subtracting a spline fit from the base of the weak peaks between $600-800$ $\mathrm{cm}^{-1}$ region of $\mathrm{En}_{92}$ and matching the areas of the two strongest peaks between 640 and $710 \mathrm{~cm}^{-1}$ to that of a film of known thickness (Fig. 3).

The estimated thickness of the normalized $E_{92}$ spectrum was $0.35 \mu \mathrm{m}$ and varying the frequency range of the area calculation indicated an uncertainty in $d$ of about $0.02 \mu \mathrm{m}$ or 6 per cent. Due to the prior normalization to $E_{92}$, the actual thickness of the midIR film was $0.29 \pm 0.02 \mu \mathrm{m}$. This procedure was then repeated for the $\mathrm{Wo}_{50} \mathrm{En}_{50}\left(\mathrm{Dp}_{100}\right)$ sample and a film thickness of $0.71 \mu \mathrm{m}$ deduced. The natural log absorbance coefficients, $\tau$, were obtained by scaling the normalized laboratory-absorbance spectra of the EnFs orthopyroxenes to the $E_{92}$ thickness, and the En-Dp-Wo and $\mathrm{Dp}-\mathrm{Hd}$ clinopyroxenes to the thickness of $\mathrm{Dp}_{100}$.

Values of the calculated mid-IR sample thicknesses are in Table A1. Knowing the original thickness helps to gauge possible rounding of the peaks in overly thick films (e.g. Hofmeister et al. 2003). Each peak in a spectrum has an associated band strength and thus a range of sample thickness exists where the band is best observed.

\subsection{Calculation of mass extinction coefficients}

We present our data as natural log absorption coefficients because this represents attenuation and path length. Mass extinction coefficients, $\kappa\left(\mathrm{cm}^{2} \mathrm{~g}^{-1}\right)$, can be calculated using the relation

$\kappa=10^{4} \tau / \rho$

where $\rho$ is the density of the mineral. Room-temperature orthopyroxene densities vary in a linear fashion with $\mathrm{Mg}: \mathrm{Fe}$ ratio between $3.2 \mathrm{gcm}^{-3}\left(\operatorname{En}_{100}\right)$ and $4.00 \mathrm{gcm}^{-3}\left(\mathrm{En}_{0}\right)$ (Deer et al. 1978). Estimated densities for each of our samples are in Table 1.

\section{OVERVIEW OF SPECTRA}

The complete $80-1200 \mathrm{~cm}^{-1}$ spectra of the orthopyroxene, enstatiteferrosilite series and the enstatite-diopside-wollastonite, and diopside-hedenbergite series are displayed in Fig. 4 along with two pigeonites and end-member wollastonite (dashed). In common with nearly all low-pressure silicates the spectra have strong $\mathrm{Si}-\mathrm{O}$ stretching modes near $1000 \mathrm{~cm}^{-1}(10 \mu \mathrm{m})$ and O-Si-O-bending modes near $500 \mathrm{~cm}^{-1}$ due to their $\mathrm{SiO}_{4}$ tetrahedra. Translations due to motions of the metal cations occur at frequencies below about $450 \mathrm{~cm}^{-1}$. Chain silicates exhibit additional and distinctive weaker bands in the $600-800 \mathrm{~cm}^{-1}(16.5-12.5 \mu \mathrm{m})$ range due to $\mathrm{Si}-\mathrm{O}-\mathrm{Si}$ bending modes in the linked oxygen atoms of the chains of silicate tetrahedra.

As observed by others (e.g. Jäger et al. 1998; Chihara et al. 2002; Bowey et al. 2007), in the En-Fs series bands generally move to lower frequencies (longer wavelength, towards the red), as $\mathrm{Mg}$ is replaced with $\mathrm{Fe}$, with larger frequency shifts occurring in the translational bands. In common with other solid-solution series, end-members $\left(E n_{99}\right.$ and $\left.E_{1}\right)$ have more and sharper peaks than intermediate members. Several bands show dramatic changes when the Fe content exceeds $\sim 50$ percent in behaviour analogous to that previously observed in the olivine series (Hofmeister \& Pitman 2007); this effect will be discussed in Section 5. It is noteworthy that only two bands are observed to move to higher frequencies (to the blue) with an increase in Fe content, these shifts are small - frequencies shift between 862 $893 \mathrm{~cm}^{-1}(11.6-11.2 \mu \mathrm{m})$ and $460-464 \mathrm{~cm}^{-1}(21.7-21.51 \mu \mathrm{m})$ and that both shifts occur only at the Mg-rich $\left(\sim \mathrm{En}_{100}-\mathrm{En}_{40}\right)$ end of the series. We generally identify similar bands and compositional trends to Chihara et al. (see Section 7). 

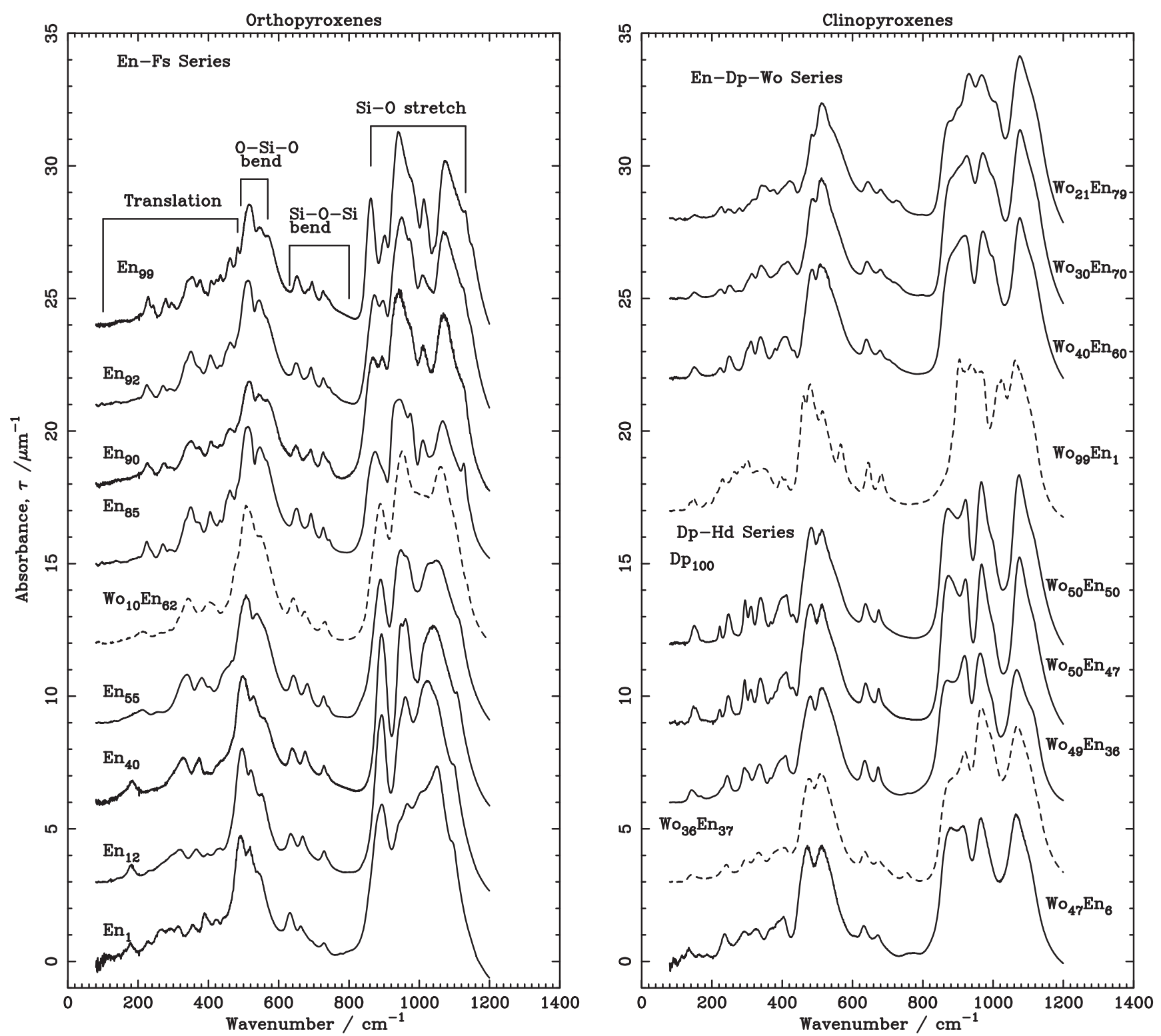

Figure 4. Left: orthopyroxenes in the enstatite-ferrosilite solid-solution series, each spectrum is offset by 3 from the spectrum below it. The spectrum of pigeonite, $\mathrm{Wo}_{10} \mathrm{En}_{62}$ resembles an En-Fs pyroxene even though it is of intermediate composition (dashed curve). Right: clinopyroxenes in the enstatitediopside-wollastonite and diopside-hedenbergite solid-solution series. Spectra of the end-member pyroxenoid wollastonite, Wo99 and the Dp-Hd-like spectrum of pigeonite $\mathrm{Wo}_{36} \mathrm{En}_{37}$ are dashed because their compositions are not on the edges of the pyroxene quadrilateral. Clinopyroxene offsets from the bottom are: Dp-Hd: 0, 3, 6, 9, 12; and En-Dp-Wo: 17, 22, 25, 28.

As in the En-Fs series, bands in the Dp-Hd series shift to lower frequencies as Fe replaces $\mathrm{Mg}$ in the monoclinic Dp-Hd series; no bands shift to higher frequencies with an increase in Fe. Peaks in the En-Dp-Wo series shift to lower frequencies with replacement of $\mathrm{Mg}$ for $\mathrm{Ca}$ because the larger cation forces expansion of the lattice. The wollastonite spectrum resembles the En-Dp spectra above $400 \mathrm{~cm}^{-1}$ because these bands represent nearest-neighbour interactions. But, due to its different long-range order wollastonite, has a very different absorption profile in the $200-400-\mathrm{cm}^{-1}$ region of the Translations. Spectra of the pigeonites are similar to pyroxenes on the nearest edges of the pyroxene-composition quadrilateral (Fig. 1). For example, the effect of 10 per cent substitution of $\mathrm{Ca}$ for $\mathrm{Mg}$ in $\mathrm{Wo}_{10} \mathrm{En}_{62}$ reduces the number of narrow bands, but does not alter the spectrum much from the rest of the En-Fs series. In contrast, more substantial replacement of $\mathrm{Mg}$ and $\mathrm{Fe}$ by $\mathrm{Ca}$ in $\mathrm{Wo}_{36} \mathrm{En}_{37}$ noticeably reduces the height of the peak near $840 \mathrm{~cm}^{-1}$, weakens the translations and adds an extra Si-O-Si band near $760 \mathrm{~cm}^{-1}$ in comparison to minerals in the Dp-Hd series. Further discussion of pigeonites and wollastonite is beyond the scope of this paper.

\section{COMPOSITION-DEPENDENT WAVELENGTH SHIFTS}

In order to identify minerals in astronomical dust it is necessary to determine the degeneracy between wavelength shifts in the spectra due to temperature and those due to changes in chemical composition. Since each band arises from part of the crystal structure (e.g. the $\mathrm{Si}-$ $\mathrm{O}-\mathrm{Si}$ bend or translations of the position of the cations relative to 
the tetrahedra) there will be ambiguity between different silicates, and between silicates and other solids containing similar bonds. An analogy would be to consider the spectral signature of rings of carbon atoms in organic molecules: a spectral feature is indicative of a part of a molecule, not the entire structure.

Changes in the $\mathrm{Si}-\mathrm{O}$ stretching, $\mathrm{Si}-\mathrm{O}-\mathrm{Si}$ bending, and $\mathrm{O}-\mathrm{Si}-\mathrm{O}-$ bending modes with composition are presented in Fig. 5 and the bands listed in Tables 2 and 3; changes in the Translations are examined in Figs 5 and 6 and the bands listed in Tables 3 and 4. The fitted compositional dependence of the peak wavelengths of prominent bands are listed in Table 5. Stronger and distinctive bands are labelled according to their likely carriers: $\mathrm{S}, \mathrm{Si}-\mathrm{O}$ stretch, $\mathrm{SiB}, \mathrm{Si}-$ $\mathrm{O}-\mathrm{Si}$ bend, $O S, \mathrm{O}-\mathrm{Si}-\mathrm{O}$ bend, and $T$, translation. Letters in front of the carrier assignment indicate the pyroxene series $o$, orthopyroxenes (En-Fs series), $c$, clinopyroxenes, $h$, Dp-Hd series, $w$, En-Dp-Wo series, $a$, all pyroxenes studied; the letter $w$ after a band name indicates a weak band. Some bands of the En-Fs series have different compositional wavelength shifts at either end of the series, bands at the Mg-rich end (En $\gtrsim 50$ per cent) are denoted by the subscript $E$, Fe-rich bands at the Fe-rich end $(\mathrm{En} \lesssim 50$ per cent $)$ are labelled $F$. Numerical subscripts increase with increasing wavelength. In the sections below wavelengths in parenthesis are the wavelength of the pyroxene with the highest $\mathrm{Mg}$ content. Due to the complexity of the pyroxene spectra, band positions were determined by close inspection of the frequency-based spectra; a fuller treatment of band shapes is beyond the scope of this paper, but will be presented together with the structural constraints on a later paper in the mineralogical literature.

\subsection{Bands common to all studied pyroxenes}

Only two narrow bands are common to all the pyroxenes (Fig. 5, and Tables 2, 3, and 5) an Si-O stretching mode, $a S$, (10.22 $\mu \mathrm{m}$; $\left.\mathrm{En}_{99}\right)$ and an $\mathrm{Si}-\mathrm{O}-\mathrm{Si}$-bending mode, $a \mathrm{SiB}$ (15.34 $\mu \mathrm{m}$; $\left.\mathrm{En}_{99}\right) . a S$ shifts by only $0.15 \mu \mathrm{m}$ as $\mathrm{Mg}$ is replaced; the band is indistinct in the orthopyroxenes, due to the dominance of a neighbouring blended band $\left(o S_{2 E}\right)$, but becomes more prominent in the clinopyroxenes when $\mathrm{Ca}$ increases from from 20 to 50 percent, and strongest for diopsides $\left(\simeq \mathrm{Wo}_{50} \mathrm{En}_{50} \mathrm{Fs}_{50}\right)$. In contrast, the common bending-mode, $\mathrm{aSiB}$, is prominent across our range of pyroxene samples and shifts by only $0.51 \mu \mathrm{m}$ to $15.85 \mu \mathrm{m}$ in $\mathrm{En}_{1}$.

\section{2 $\mathrm{Si}-\mathrm{O}$ stretches}

The orthopyroxene bands (Figs $5 \mathrm{a}+\mathrm{g}$, and Tables 2 and 5) are: $o S_{1},\left(9.32 \mu \mathrm{m} ; \mathrm{En}_{99}\right), o S_{2 E}\left(10.64 \mu \mathrm{m} ; \mathrm{En}_{99}\right)$, and $\mathrm{oS}_{3}(11.60 \mu \mathrm{m}$; $E_{99}$ ) which is subdivided into two components, $\mathrm{oS}_{3 E}$ and $\mathrm{oS}_{3 F}$. Increases in the proportion of Fe reduce the overall width of the whole stretching feature due to the shift of $o S_{1}$ by $+0.47 \mu \mathrm{m}$ and the decrease in the wavelength of band $o S_{3 E}$ from $11.60 \mu \mathrm{m}\left(\mathrm{En}_{99}\right)$ to $11.20 \mu \mathrm{m}\left(\mathrm{En}_{40}\right)$. In contrast, band $o S_{3 F}$ remains at $11.2 \mu \mathrm{m}$ does not shift in wavelength between $\mathrm{En}_{40}$ and $\mathrm{En}_{1}$. Both the wavelength and width of the band resemble those of peaks seen in many astronomical sources in which the carrier is frequently identified as olivine (e.g. in comets, Hanner, Lynch \& Russell 1994) or occasionally as a polyaromatic-hydrocarbon absorption feature (Bregman, Hayward \& Sloan 2000). It could also contribute to the shoulder identified as olivine Mg-end-member forsterite (e.g. Do-Duy et al. 2020) in YSOs and the ISM. The 10.64-10.55- $\mu \mathrm{m} o S_{2 E}$ band shifts by only $+0.1 \mu \mathrm{m}$ between $\mathrm{En}_{99}$ and $\mathrm{En}_{40}$ and probably merges with $a S$ at En 12 per cent.
The characteristic Si-O-stretching bands of Ca-bearing clinopyroxenes (Figs 5d + g, and Tables 2 and 5) are: $a S$ and $c S(9.29 \mu \mathrm{m}$; $\left.\mathrm{Wo}_{21} \mathrm{En}_{79}\right)$. In addition, the En-Dp series has band $w S(10.74 \mu \mathrm{m}$; $\left.\mathrm{En}_{79}-\mathrm{En}_{40}\right)$ which shifts by $+0.15 \mu \mathrm{m}$ and the Dp-Hd series, $h S\left(10.86 \mu \mathrm{m} ; \mathrm{En}_{50}-\mathrm{En}_{6}\right)$ shifts by only $+0.08 \mu \mathrm{m}$ across the series. Clinopyroxenes with diopside-like compositions $\left(\mathrm{Wo}_{30} \mathrm{En}_{70}\right.$ to $\mathrm{Wo}_{49} \mathrm{En}_{36}$ ) have a prominent shoulder, $d S$ at $11.43-11.55 \mu \mathrm{m}$. In common with the orthopyroxenes, the width of the overall Dp-Hd series $\mathrm{Si}-\mathrm{O}$ stretching region becomes narrower with increasing $\mathrm{Fe}$ content.

Wavelength shifts of $a S, c S$ and $h S$ have a similar dependence on the percentage of $\mathrm{Mg} \sim 0.002 \times x$, where $x$ is the percentage of $\mathrm{Mg}$ (Fig. 5g and Table 5).

\subsection{Si-O-Si bend}

These modes are produced in the linkages between $\mathrm{SiO}_{4}$ tetrahedra; we observed three prominent bands in orthopyroxenes (Figs $5 b+h$ ), but only two bands in clinopyroxenes (Figs $5 \mathrm{e}+\mathrm{h}$; and Tables 3 and 5). The three orthopyroxene bands are $a \mathrm{SiB}\left(15.34 \mu \mathrm{m} ; \mathrm{En}_{99}\right)$, $o \mathrm{Si}_{1}\left(13.77 \mu \mathrm{m} ; \mathrm{En}_{99}\right)$, and $o \mathrm{SiB}_{2}\left(14.39 \mu \mathrm{m} ; \mathrm{En}_{99}\right)$; there is also a weak band $o S_{i} B_{w}\left(13.46 \mu \mathrm{m} ; \mathrm{En}_{99}\right)$ in $\mathrm{En}_{99}$ to $\mathrm{En}_{12} . o S i B_{w}$ and $o \mathrm{Si}_{1}$ barely shift with composition $(\leq 0.04 \mu \mathrm{m})$ but $o \mathrm{SiB}_{2}$ shifts by $0.69 \mu \mathrm{m}$. The clinopyroxenes and pyroxenoid have two Si-OSi bands: $a \mathrm{SiB}$ and $c \mathrm{SiB}\left(14.71 \mu \mathrm{m}\right.$ in $\left.\mathrm{Wo}_{21} \mathrm{En}_{79}\right) ; c \mathrm{SiB}$ shifts by $0.17 \mu \mathrm{m}$ across the range to $\mathrm{Wo}_{47} \mathrm{En}_{6}$.

The Si-O-Si bending modes might be the most promising region for the identification of chain silicates in the 5-28- $\mu \mathrm{m}$ spectral range of the Mid-Infrared Instrument (MIRI) on the James Webb Space Telescope (JWST) because the spectra of other silicate groups previously studied by us are quite different between 12 and $16 \mu \mathrm{m}$ : olivines do not display these bands due to the absence of tetrahedral linkages (e.g. Hofmeister \& Pitman 2007) and of the hydrous silicates, talc has only one narrow band at $14.92 \mu \mathrm{m}$ which might overlap with some of the diopsides, and amphiboles have only a single band at $13.15 \mu \mathrm{m}$ (Hofmeister \& Bowey 2006); silicas $\left(\mathrm{SiO}_{2}\right.$ minerals) have narrow bands at 12.5-12.8 and 14.4$14.6 \mu \mathrm{m}$ (Koike et al. 2013) which are different from the pyroxene bands.

\subsection{O-Si-O bends}

For this motion, orthopyroxenes have three narrow bands, whereas clinopyroxenes have two broader bands.

The orthopyroxene bands (Figs $5 \mathrm{c}+\mathrm{i}$, and Tables 3 and 5) are: $o O B_{1}\left(17.54 \mu \mathrm{m} ; \mathrm{En}_{99}\right)$ which shifts by $0.81 \mu \mathrm{m}$ between $\mathrm{En}_{99}$ and $\mathrm{En}_{1}$ and $o O B_{2}\left(18.28 \mu \mathrm{m} ; \mathrm{En}_{99}\right)$ and $o O B_{3}\left(19.42 \mu \mathrm{m} ; \mathrm{En}_{99}\right)$ which both shift by $0.99 \mu \mathrm{m}$. The behaviour of the clinopyroxene bands (Figs $5 \mathrm{f}+\mathrm{i}$, and Tables 3 and 5) is different: the common $c O B$ band $\left(19.49 \mu \mathrm{m} ; \mathrm{Wo}_{21} \mathrm{En}_{79}\right)$ does not shift significantly with composition, the Dp-Hd-band, $h O B\left(20.75 \mu \mathrm{m}\right.$; $\left.\mathrm{Dp}_{100}\right)$ shifts by $0.48 \mu \mathrm{m}$ across the range $\mathrm{En}_{50}-\mathrm{En}_{6}$ whilst the En-Dp-band $w_{O B}$ decreases in wavelength by $0.44 \mu \mathrm{m}$ as $\mathrm{Ca}$ replaces $\mathrm{Mg}\left(\mathrm{En}_{79}\right.$ to $\left.\mathrm{En}_{60}\right)$. The non-shifting $c O B$-band overlaps $o O B_{3}$ above $\mathrm{En}_{90}$ : so a similarly shaped feature at $20.0-20.4 \mu \mathrm{m}$ could indicate an orthpyroxene with $\mathrm{En} \lesssim 60$ per cent.

\subsection{Translations}

Translational bands exhibit the largest wavelength shifts with composition because cations are less tightly bound than are the chains of $\mathrm{SiO}_{4}$ tetrahedra. Two orthopyroxene translations (Figs 5c, f, and 
Table 2. Si-O stretch - peak wavelengths of bands. Pigeonites of intermediate composition and bands not used in fitting are indicated with bracketed italics. Bands with large compositional wavelength shifts are indicated in bold. Scatter in the measurements indicates an uncertainty of $\pm 0.015 \mu \mathrm{m}$.

\begin{tabular}{|c|c|c|c|c|c|c|c|c|c|}
\hline \multirow[t]{2}{*}{ Sample } & \multicolumn{9}{|c|}{ Band assignment and measured wavelength $(\mu \mathrm{m})$} \\
\hline & & & $o S_{1}$ & & & $a S$ & $o S_{2 E}$ & & $o S_{3 E}$ \\
\hline En$_{99}$ & 8.70 & 8.83 & 9.32 & & 9.87 & 10.22 & 10.64 & 11.10 & 11.60 \\
\hline $\mathrm{En}_{92}$ & & 8.90 & 9.35 & & 9.91 & 10.29 & 10.54 & 11.15 & 11.47 \\
\hline $\mathrm{En}_{90}$ & & 8.90 & 9.36 & & 9.90 & & 10.63 & 11.19 & 11.53 \\
\hline $\mathrm{En}_{85}$ & & 8.87 & 9.38 & & 9.90 & 10.26 & 10.64 & & 11.44 \\
\hline$\left(W o_{10} E n_{62}\right)$ & & $(8.80)$ & $(9.43)$ & & & & $(10.52)$ & & \\
\hline \multirow[t]{2}{*}{$\mathrm{En}_{55}$} & & 9.00 & 9.53 & & & 10.36 & 10.56 & & $\begin{array}{c}(11.24) \\
\mathbf{1 1 . 2 4}\end{array}$ \\
\hline & & & & & & & & & $o S_{3 F}$ \\
\hline $\mathrm{En}_{40}$ & & 9.03 & 9.64 & & & 10.41 & 10.55 & & 11.20 \\
\hline $\mathrm{En}_{12}$ & & 9.11 & 9.79 & & & 10.43 & & & 11.20 \\
\hline \multirow[t]{2}{*}{$\mathrm{En}_{1}$} & & 9.16 & & 9.51 & 9.97 & 10.37 & & & 11.20 \\
\hline & & & $\mathrm{cS}$ & & & & $w S$ & & $\mathrm{dS}$ \\
\hline \multirow[t]{2}{*}{$\mathrm{Wo}_{21} \mathrm{En}_{79}$} & & & 9.29 & & 9.92 & 10.33 & 10.74 & 11.15 & \\
\hline & & & & & & & & & (11.48) \\
\hline $\mathrm{Wo}_{30} \mathrm{En}_{70}$ & & & 9.29 & & 9.99 & 10.30 & 10.81 & & 11.43 \\
\hline \multirow[t]{2}{*}{$\mathrm{Wo}_{40} \mathrm{En}_{60}$} & & & 9.29 & & 10.02 & 10.30 & 10.89 & & 11.45 \\
\hline & & & & & & & $h S$ & & \\
\hline $\mathrm{Wo}_{50} \mathrm{En}_{50}$ & & & 9.31 & & & 10.34 & 10.86 & & 11.48 \\
\hline $\mathrm{Wo}_{50} \mathrm{En}_{47}$ & & & 9.30 & & & 10.34 & 10.86 & & 11.47 \\
\hline \multirow[t]{2}{*}{$\left(W_{36} E n_{37}\right)$} & & & $(9.35)$ & & & (10.35) & (10.88) & & \\
\hline & & & & & & & & & (11.48) \\
\hline $\mathrm{Wo}_{49} \mathrm{En}_{36}$ & & & 9.37 & & & 10.37 & 10.89 & & 11.55 \\
\hline \multirow[t]{2}{*}{$\mathrm{Wo}_{47} \mathrm{En}_{6}$} & & & 9.39 & & & 10.36 & 10.94 & & \\
\hline & & & & & & & & & (11.40) \\
\hline \multicolumn{10}{|c|}{ Pyroxenoid (no band assignments) } \\
\hline Wo99 & & & 9.41 & 9.75 & 9.86 & 10.36 & 10.66 & 11.06 & \\
\hline
\end{tabular}

Table 3. O-Si-O, Si-O-Si bends, and the highest frequency orthopyroxene translation, uncertainty in wavelength $\sim \pm 0.02 \mu \mathrm{m}$ near $13 \mu \mathrm{m}$ and $\sim \pm 0.04 \mu \mathrm{m}$ at $20 \mu \mathrm{m}$.

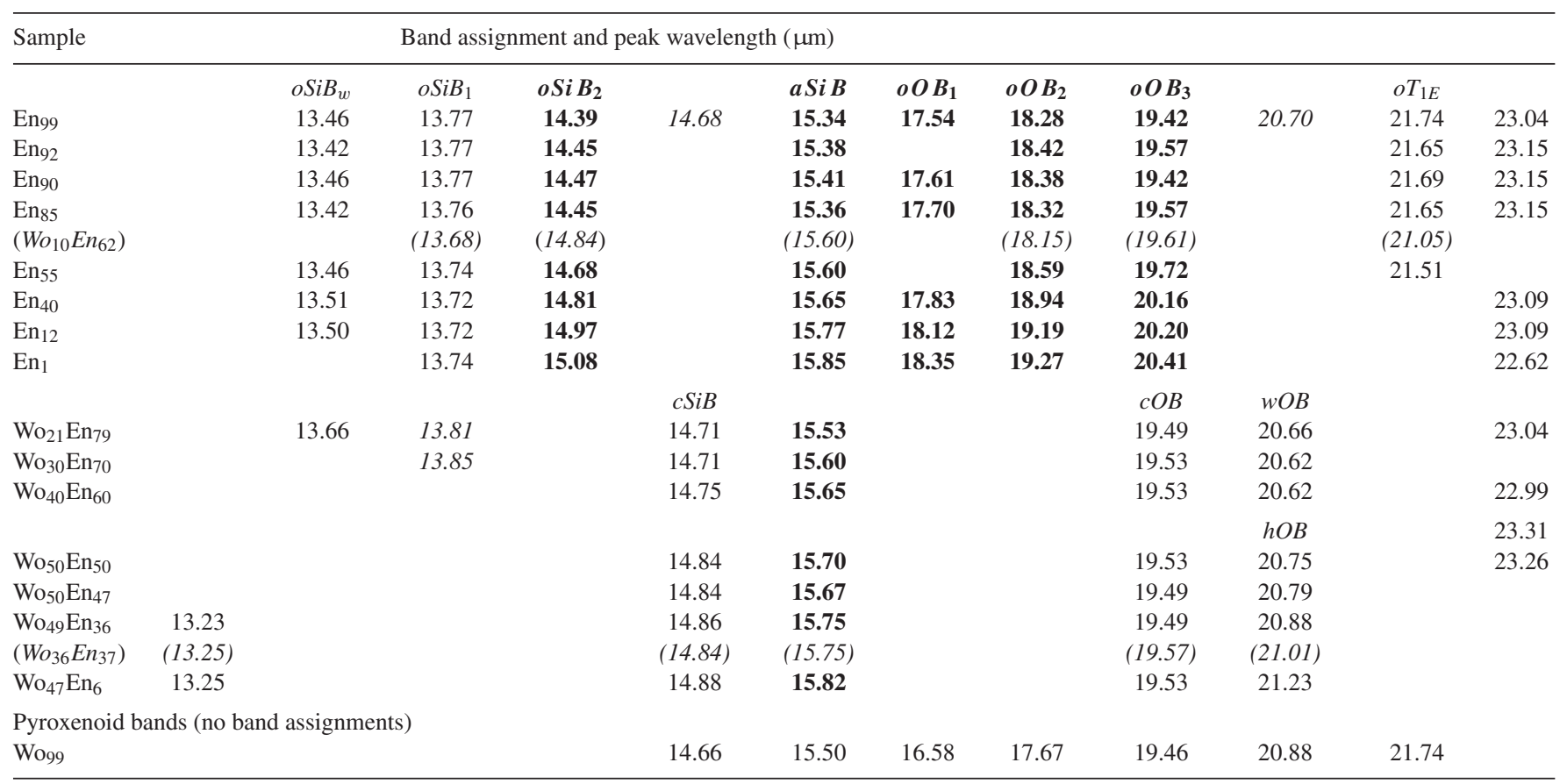

$\mathrm{i}$ and $6 \mathrm{a}, \mathrm{b}, \mathrm{e}$, and $\mathrm{f}$ ) have small shifts in the $\mathrm{En}_{99}-\mathrm{En}_{55}$-range: $o T_{1 E}\left(21.74 \mu \mathrm{m} ; \mathrm{En}_{99}\right)$ decreases in wavelength by $0.23 \mu \mathrm{m}$, while and $o T_{3 E}\left(26.60 \mu \mathrm{m} ; \mathrm{En}_{99}\right)$ moves by $+0.14 \mu \mathrm{m}$. In contrast, bands $o T_{2}\left(24.57 \mu \mathrm{m} ; \mathrm{En}_{99}\right)$ and $o T_{4}\left(28.25 \mu \mathrm{m} ; \mathrm{En}_{99}\right)$ each shift by $\sim 3.5 \mu \mathrm{m}$ across the $\mathrm{En}_{99}-\mathrm{En}_{1}$-range. $o T_{5}\left(35.84 \mu \mathrm{m} ; \mathrm{En}_{99}\right)$ has the largest shift of any pyroxene band: $8.02 \mu \mathrm{m} \mathrm{En}_{99}-\mathrm{En}_{1}$. Chihara 

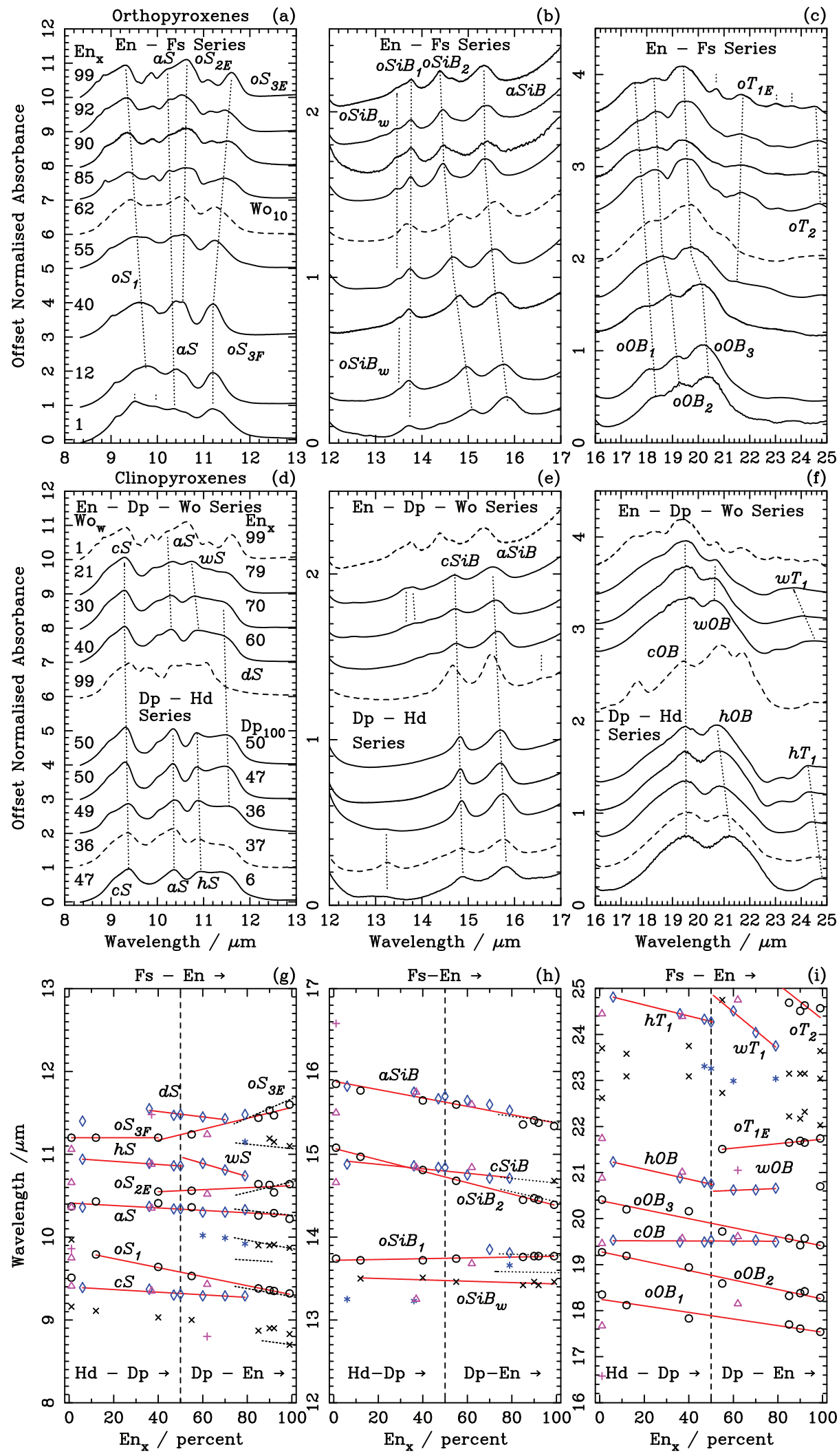

Figure 5. Left to right: detail in the $\mathrm{Si}-\mathrm{O}$ stretching, $\mathrm{Si}-\mathrm{O}-\mathrm{Si}$ bending modes, $\mathrm{O}-\mathrm{Si}-\mathrm{O}$ bending modes, and the highest frequency translations of ortho- and clinopyroxenes. Bottom row: peak positions as a function of $\mathrm{Mg}$ content: solid red lines are fits to the strongest peak shifts, black dotted lines are fits to the peak shifts in meteoritic spectra obtained by Bowey et al. (2007). Open symbols indicate prominent bands: En-Fs orthopyroxenes - black O, $\times$; En-Dp and Dp-Hd clinopyroxenes - blue $\diamond, *$ and pigeonites and wollastonite - magenta $\Delta,+$. 

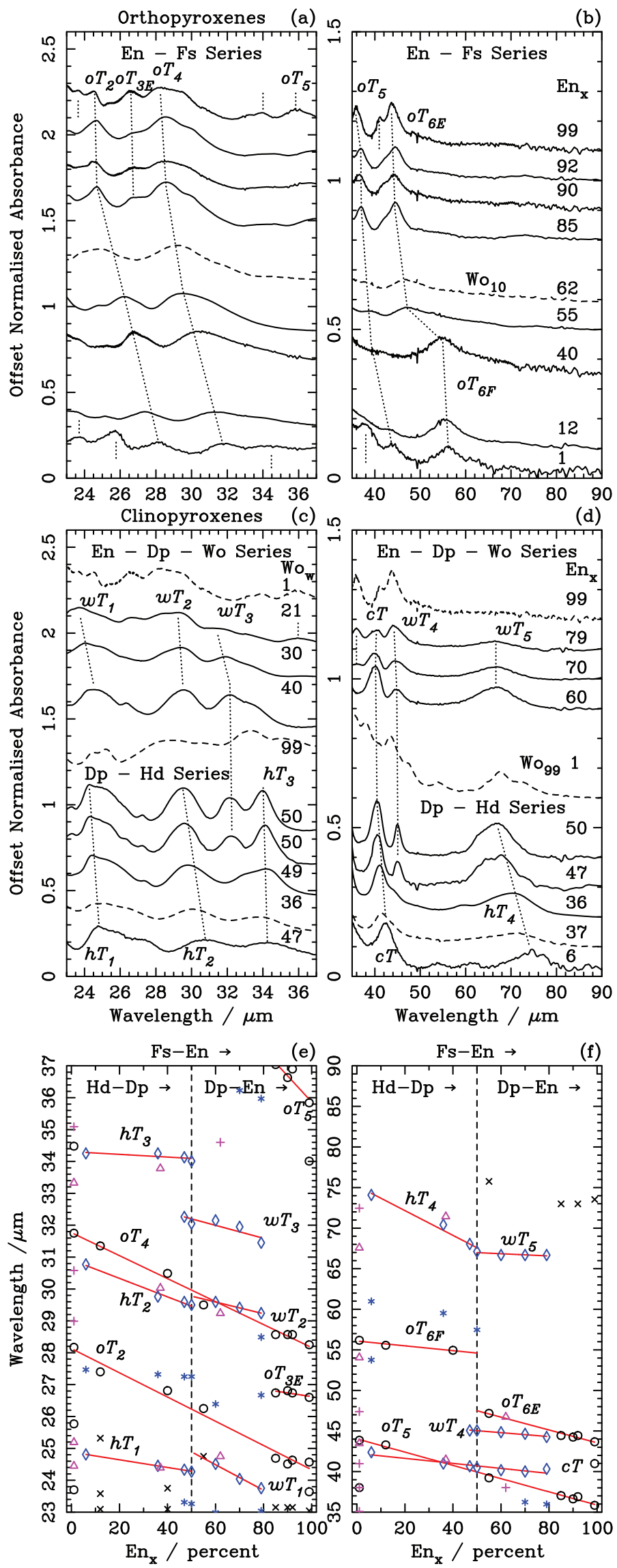

Figure 6. Detail in the Translational bands. Bottom row: peak positions as a function of Mg content. See Fig. 5 for key to plotting symbols. 
Table 4. Translations. Uncertainty at $20 \mu \mathrm{m} \pm 0.04$, for the broad clinopyroxene $60 \mu \mathrm{m}$ peak is $\pm 0.5 \mu \mathrm{m}$. The orthopyroxene peaks above $70 \mu \mathrm{m}$ are ill-defined in our data (see Section 6.2).

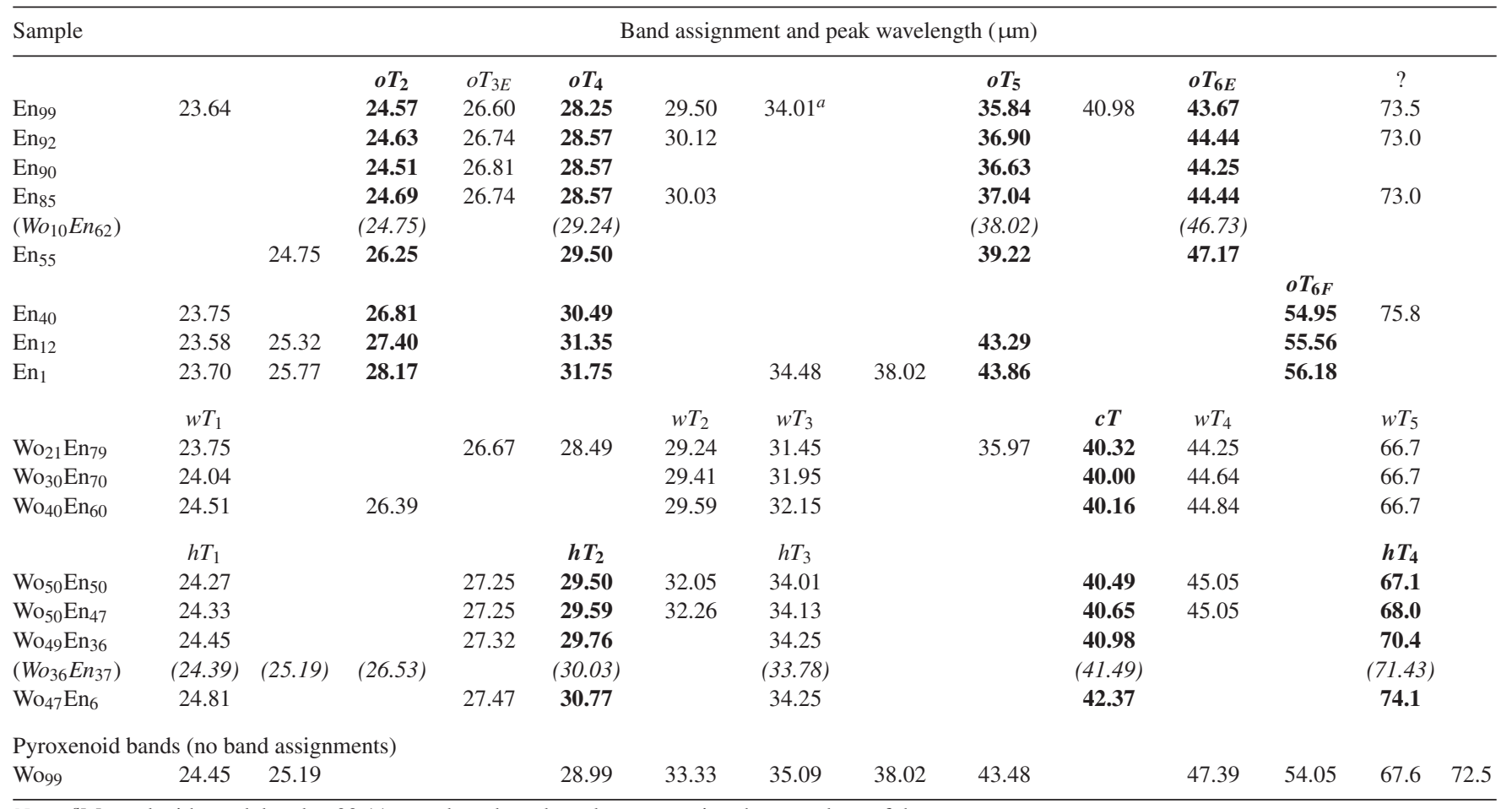

Note: ${ }^{a}$ Merged with weak band at 33.11 , very broad weak peaks are seen in other members of the group.

et al. found the largest shift was for a band at $43 \mu \mathrm{m}$ in $\mathrm{En}_{100}$ which moved to $56 \mu \mathrm{m}$ in $\mathrm{En}_{0}$. With our wider range of orthopyroxenes, we find that this band has two disjointed components: $o T_{6 E}$ which shifts from $43.7 \mu \mathrm{m}\left(\mathrm{En}_{99}\right)$ to $47.2 \mu \mathrm{m}\left(\mathrm{En}_{55}\right)$ and $o T_{6 F}$ which occurs at $55.0 \mu \mathrm{m}\left(\mathrm{En}_{40}\right)$ and $56.2 \mu \mathrm{m}\left(\mathrm{En}_{1}\right)$ giving a combined shift of $12.5 \mu \mathrm{m}$.

The clinopyroxene series' (Figs 6c and d) have only one common translation, $c T$, $\left(40.32 \mu \mathrm{m}\right.$; $\left.\mathrm{Wo}_{21} \mathrm{En}_{79}\right)$ which shifts by $2.05 \mu \mathrm{m}$ across the $\mathrm{En}_{79}-\mathrm{En}_{6}$ range. The shifts of $\mathrm{En}-\mathrm{Dp}$ pyroxenes are relatively small: $w T_{1}\left(23.75 \mu \mathrm{m} ; \mathrm{Wo}_{21} \mathrm{En}_{79}\right)$ and $w T_{2}(29.24 \mu \mathrm{m}$; $\mathrm{Wo}_{21} \mathrm{En}_{79}$ ) shift in the $\mathrm{En}_{79}-\mathrm{En}_{60}$ range, by 0.76 and $0.35 \mu \mathrm{m}$, respectively. $w T_{2}$ shifts in parallel with $w T_{3}\left(31.45 \mu \mathrm{m} ; \mathrm{Wo}_{21} \mathrm{En}_{79}\right)$ and $w T_{4}\left(44.25 \mu \mathrm{m} ; \mathrm{Wo}_{21} \mathrm{En}_{79}\right)$ which vary by $\sim 0.002 \times x$ down to $x=47 . w T_{5}(66.7 \mu \mathrm{m})$ is the broadest band measured $(\sim 10 \mu \mathrm{m})$, but shifts by only $0.44 \mu \mathrm{m}$ despite its long peak-wavelength.

In common with the orthopyroxenes, Dp-Hd clinopyroxenes show much more variable shifts: $h T_{1}\left(24.27 \mu \mathrm{m} ; \mathrm{Dp}_{100}\right)$ and $h T_{3}(34.01 \mu \mathrm{m}$; $\left.\mathrm{Dp}_{100}\right)$ shift by 0.54 and $0.24 \mu \mathrm{m}$, respectively $h T_{2}\left(29.5 \mu \mathrm{m} ; \mathrm{Dp}_{100}\right)$ has a similar slope to $c T$, and the total shift is $1.27 \mu \mathrm{m}$. However, the most striking difference in the clinopyroxene shifts is that in contrast to the $w T_{5}$ band of En-Dp clinopyroxenes, the broadest and lowest frequency band of the Dp-Hd series $h T_{4}\left(67.1 \mu \mathrm{m}\right.$; Dp $\left.p_{100}\right)$ has a large wavelength shift of $7.0 \mu \mathrm{m}$ between $\mathrm{En}_{50}$ and $\mathrm{En}_{6}$.

\section{LIMITATIONS IN OUR DATA SET}

\subsection{Undetectable effect of clinopyroxene on $\mathrm{En}_{99}$}

Hofmeister (2012) found that the meteoritic sample from which $\mathrm{En}_{99}$ is derived contains 5 percent of microscopic inclusions (blebs) of composition $\left.\mathrm{Mg}_{1.10} \mathrm{Ca}_{0.85} \mathrm{Na}_{0.02} \mathrm{Al}_{0.02}\right) \mathrm{Si}_{2} \mathrm{O}_{6} \equiv \mathrm{Wo}_{43} \mathrm{En}_{55}$, a level, just above canonical detection limit in infrared spectra. Unfortunately, we do not have a spectrum of $\mathrm{Wo}_{43} \mathrm{En}_{55}$ to compare with our data and we do not know if the thin film made from sample was similarly contaminated. The spectrum of $\mathrm{En}_{99}$ contains extra peaks that do not appear in the rest of the En-Fs orthopyroxene series. However, this could be because it is of end-member composition. Bands which look like clinopyroxene peaks are a shoulder at $14.68 \mu \mathrm{m}(c \mathrm{SiB})$, and fairly prominent peaks at $20.70 \mu \mathrm{m}(w O B / h O B), 34.01 \mu \mathrm{m}\left(h T_{3}\right)$ and $40.98 \mu \mathrm{m}(c T)$. These features were also identified by Chihara et al. in their magnesium-rich synthetic samples which contained no $\mathrm{Wo}_{43} \mathrm{En}_{55}$, therefore we consider these bands intrinsic to $\mathrm{En}_{99}$ and not the result of contamination.

\subsection{Unobserved bands above $70 \mu \mathrm{m}$}

Bowey et al. (2001) detected a weak pair of bands in $\mathrm{En}_{85}$ centred at 71.01 and $73.83 \mu \mathrm{m}$ at room temperature which are not properly distinguishable from the noise in the current data. There are hints of structure near $73 \mu \mathrm{m}$ in $\mathrm{En}_{99}, \mathrm{En}_{92}, \mathrm{En}_{85}$, and at $75.8 \mu \mathrm{m}$ in $\mathrm{En}_{55}$. The most likely cause of their absence is an insufficiently thick film and low detector signal-to-noise ratios. It would be particularly useful to fully explore this spectral range because Chihara et al. measured differences between clino- and orthoenstatite at longer wavelengths, namely pairs of bands at 49.2 and $51.6 \mu \mathrm{m}$, and 68.7 and $72.5 \mu \mathrm{m}$ in orthoenstatite (Oen; $o E n_{100}$ ) which were not observed in clinoenstatite $\left(\mathrm{Cen} ; \mathrm{cEn}_{100}\right)$; clinoenstatite had a narrow band at $65.9 \mu \mathrm{m}$. The Cen and Oen spectra were identical at wavelengths $\lesssim 40 \mu \mathrm{m}$. The longest band they identified was a peak at $86.1 \mu \mathrm{m}$ in $\mathrm{En}_{0}$. 
Table 5. Dependance of the peak positions of stronger and distinctive bands on the proportion of $\mathrm{Mg}$ in the pyroxenes. Bands with the largest wavelength shifts are highlighted in bold, those with negligible wavelength shifts, or small wavelength shifts with low Pearson correlation coefficients $\left|R^{2}\right|<0.7$ are italicized.

\begin{tabular}{|c|c|c|c|c|c|c|}
\hline Series & Label $^{a}$ & $\begin{array}{c}\lambda \\
E n_{\max }\end{array}$ & $\begin{array}{l}\text { Range } \\
\text { per cent }\end{array}$ & $\begin{array}{l}\Delta \lambda^{b} \\
\mu \mathrm{m}\end{array}$ & $\begin{array}{c}\text { Fit } \\
\mathrm{En}_{0}+b \mathrm{En}_{x}\end{array}$ & $\left|R^{2}\right|$ \\
\hline \multicolumn{7}{|c|}{ Si-O stretch } \\
\hline All & $a S$ & 10.22 & $99-1$ & 0.15 & $10.412-0.0015$ & 0.8 \\
\hline \multirow[t]{4}{*}{ En-Fs } & $o S_{1}$ & 9.32 & 99-12 & 0.47 & $9.850-0.0055$ & 1 \\
\hline & $o S_{2 E}$ & 10.64 & $99-40$ & 0.09 & $10.500+0.0012$ & 0.6 \\
\hline & $o S_{3 E}$ & 11.60 & 99-40 & -0.40 & $10.908+0.0066$ & 1 \\
\hline & $o S_{3 F}$ & 11.20 & $40-1$ & 0.00 & 11.20 & - \\
\hline \multirow[t]{2}{*}{ Clino } & $c S$ & 9.29 & $79-6$ & 0.10 & $9.398-0.0016$ & 0.9 \\
\hline & $d S$ & 11.43 & $70-36$ & 0.12 & $11.648-0.0033$ & 0.9 \\
\hline En-Wo & $w S$ & 10.74 & $79-40$ & 0.15 & $11.364-0.0079$ & 1 \\
\hline Dp-Hd & $h S$ & 10.86 & $50-6$ & 0.08 & $10.952-0.0019$ & 1 \\
\hline \multicolumn{7}{|c|}{ Si-O-Si bend } \\
\hline All & $a S i B$ & 15.34 & 99- 1 & 0.51 & $15.882-0.0050$ & 0.9 \\
\hline \multirow[t]{3}{*}{ En-Fs } & $o S i B_{w}$ & 13.46 & $99-12$ & 0.04 & $13.517-0.0008$ & 0.8 \\
\hline & $o S i B_{1}$ & 13.77 & $99-1$ & -0.03 & $13.720+0.0005$ & 0.9 \\
\hline & $o S i B_{2}$ & 14.39 & 99- 1 & 0.69 & $15.072-0.0069$ & 1 \\
\hline Clino & $c S i B$ & 14.71 & $79-6$ & 0.17 & $14.933-0.0027$ & 0.9 \\
\hline \multicolumn{7}{|c|}{ O-Si-O bend } \\
\hline \multirow[t]{3}{*}{ En-Fs } & $o O B_{1}$ & 17.54 & 99- 1 & 0.81 & $18.249-0.0072$ & 1 \\
\hline & $o O B_{2}$ & 18.28 & 99- 1 & 0.99 & $19.285-0.010$ & 1 \\
\hline & $o O B_{3}$ & 19.42 & 99- 1 & 0.99 & $20.393-0.0099$ & 1 \\
\hline Clino- & $c O B$ & 19.49 & $79-6$ & 0.04 & $19.520-0.0001$ & 0.2 \\
\hline En-Wo & $w O B$ & 20.66 & $79-60$ & -0.04 & $20.489+0.0021$ & 0.9 \\
\hline Dp-Hd & $h O B$ & 20.75 & $50-6$ & 0.48 & $21.290-0.011$ & 1 \\
\hline \multicolumn{7}{|c|}{ Translations } \\
\hline \multirow[t]{7}{*}{ En-Fs } & $o T_{1 E}$ & 21.74 & $99-55$ & -0.23 & $21.240+0.0048$ & 1 \\
\hline & $o T_{2}$ & 24.57 & 99- 1 & 3.60 & $28.130-0.038$ & 1 \\
\hline & $o T_{3 E}$ & 26.60 & $99-85$ & 0.14 & $27.769-0.011$ & 0.8 \\
\hline & $o T_{4}$ & 28.25 & 99- 1 & 3.50 & $31.766-0.036$ & 1 \\
\hline & $o T_{5}$ & 35.84 & 99- 1 & 8.02 & $44.027-0.082$ & 1 \\
\hline & $o T_{6 E}$ & 43.67 & $99-55$ & 3.50 & $51.45-0.079$ & 1 \\
\hline & $o T_{6 F}$ & 55.0 & $40-1$ & 1.23 & $56.09-0.03$ & 1 \\
\hline clino- & $c T$ & 40.32 & $79-6$ & 2.05 & $42.25-0.031$ & 0.9 \\
\hline \multirow[t]{5}{*}{ En-Wo } & $w T_{1}$ & 23.75 & $79-60$ & 0.76 & $26.896-0.040$ & 1 \\
\hline & $w T_{2}$ & 29.24 & $79-60$ & 0.35 & $30.696-0.018$ & 1 \\
\hline & $w T_{3}$ & 31.45 & $79-47$ & 0.81 & $33.213-0.020$ & 0.9 \\
\hline & $w T_{4}$ & 44.25 & $79-47$ & 0.78 & $46.26-0.024$ & 1 \\
\hline & $w T_{5}$ & 66.7 & $79-50$ & 0.44 & $67.67-0.01$ & 0.8 \\
\hline \multirow[t]{4}{*}{ Dp-Hd } & $h T_{1}$ & 24.27 & $50-6$ & 0.54 & $24.883-0.012$ & 1 \\
\hline & $h T_{2}$ & 29.50 & $50-6$ & 1.27 & $30.912-0.029$ & 1 \\
\hline & $h T_{3}$ & 34.01 & $50-6$ & 0.24 & $34.307-0.0042$ & 0.7 \\
\hline & $h T_{4}$ & 67.1 & $50-6$ & 7.0 & $75.20-0.2$ & 1 \\
\hline
\end{tabular}

Notes: ${ }^{a}$ Bands are labelled according to their likely carriers:S, Si-O stretch, $\mathrm{SiB}, \mathrm{Si}-\mathrm{O}-\mathrm{Si}$ bend, $O S$, $\mathrm{O}-\mathrm{Si}-\mathrm{O}$ bend, and $T$, translation. Letters in front of the carrier assignment indicate the pyroxene series $o$, orthopyroxenes (En-Fs series), $c$, clinopyroxenes, $h$, Dp-Hd series, $w$, En-Dp-Wo series, $a$, all pyroxenes studied; the letter $w$ after a band name indicates a weak band. Some bands of the En-Fs series have different compositional wavelength shifts at the En and Fs ends of the series, bands at the Mg-rich-end (En $\gtrsim 50$ percent) are denoted by the additional subscript $E$, bands at the Fe-rich end $(\mathrm{En} \lesssim 40$ per cent $)$ are denoted with $F$. Numerical subscripts increase with increasing wavelength.

${ }^{b} \Delta \lambda=\lambda\left(E n_{\max }\right)-\lambda\left(E n_{\min }\right)$, where $E n_{\max }$ and $E n_{\min }$ are the maximum and minimum percent fractions, respectively. 

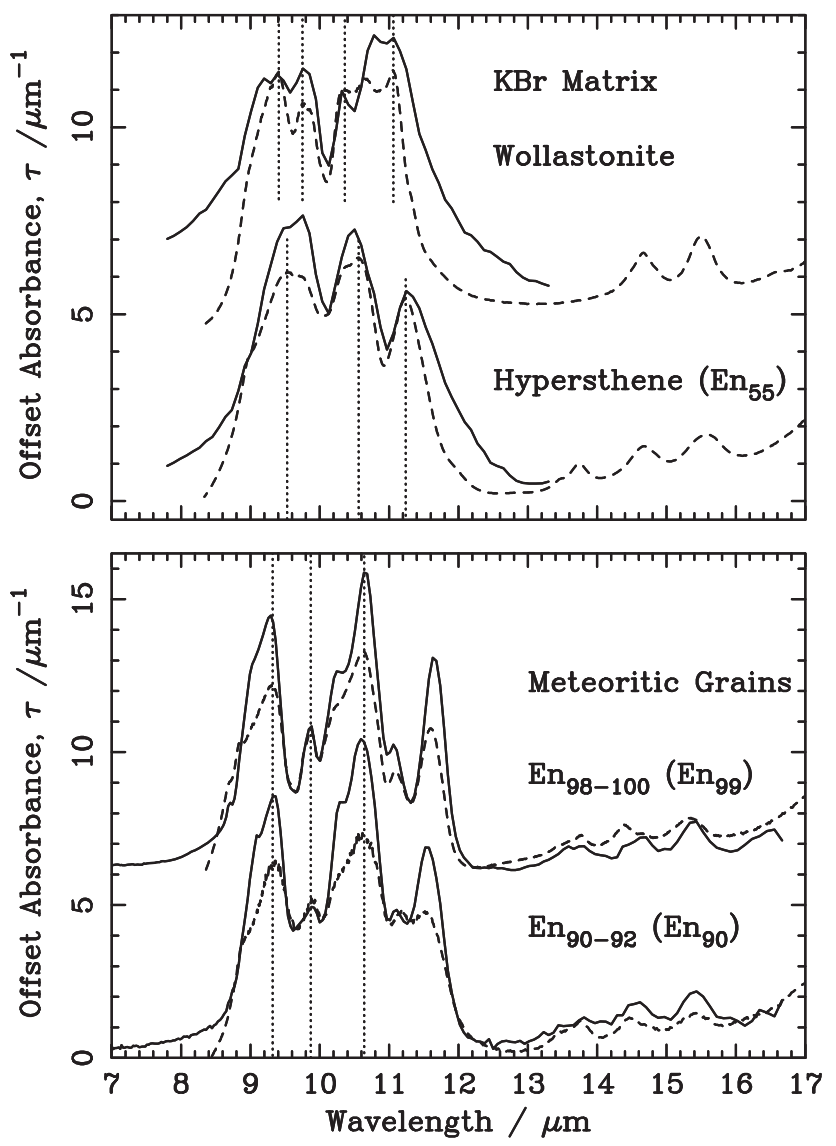

Figure 7. Comparison of DAC spectra (dashed curves) with Ferraro $\mathrm{KBr}$ pellet-spectra (solid curves) and with those of individual crushed meteoritic grains (solid curves) obtained in a DCC (Bowey et al. 2007). The ratios between strong and weak peaks change as does the spectral contrast, but the features are not wavelength shifted provided the minerals have similar chemical compositions.

\section{CONSISTENCY OF ROOM-AND LOW-TEMPERATURE PARTICULATE SPECTRA}

\subsection{Comparison with room temperature data obtained with $\mathrm{KBr}$ and polyethylene pellets}

The DAC spectra are compared with published KBr-pellet spectra of similar terrestrial pyroxenes in Figs 7 and 8 . The Ferraro spectra were obtained with the $\mathrm{KBr}$-pellet technique (grain sizes are unknown, but small enough to produce consistent peaks) and digitized for comparison with low-resolution astronomical spectra (Bowey \& Adamson 2002). The ratios between strong and weak peaks change as does the spectral contrast, but features are not wavelength shifted provided the pyroxenes have similar chemical compositions. Spectra obtained with the $\mathrm{KBr}$ technique have recognizably similar shapes to the DAC spectra and the peaks are not wavelength shifted. The $\mathrm{KBr}$ spectra are broader than our data due to the scattering of light at boundaries between the grains and the matrix. If differences in refractive index are substantial at grain boundaries some light will be reflected back along its path as it passes into the grain and again as it passes back into the $\mathrm{KBr}$. It is difficult to control particle density and clumping in a $\mathrm{KBr}$ dispersion: if these parameters are too large the measured bandwidths will increase due to the increased scattering, even if the majority of grains are sufficiently small. In the DAC the

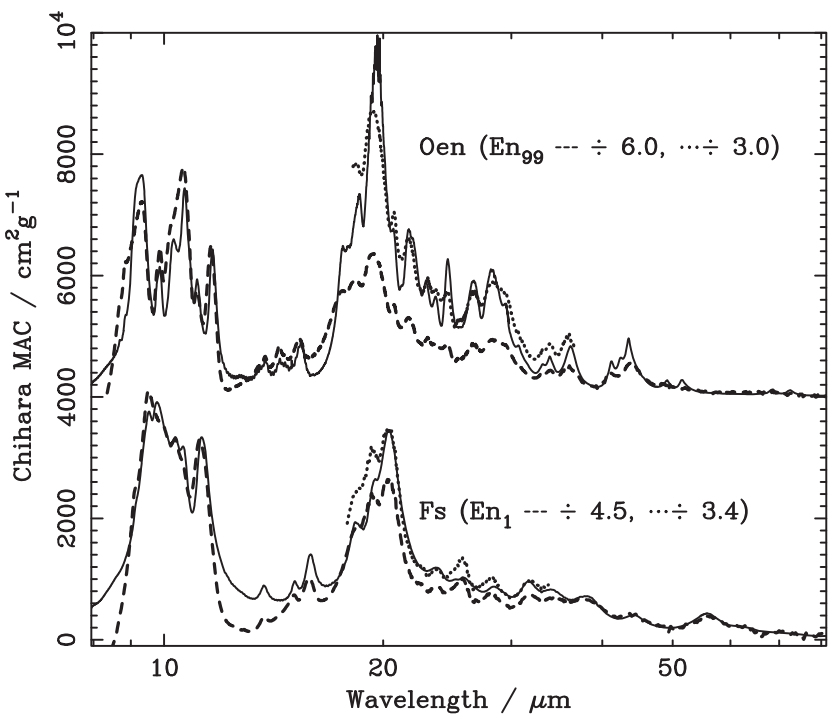

Figure 8. Comparison with Chihara et al. $\mathrm{KBr}$ and polyethylene pellet data (solid curves) for synthetic orthoenstatite $\left(\mathrm{Oen} \equiv \mathrm{En}_{100}\right)$ and ferrosilite $(\mathrm{Fs} \equiv$ $\left.\mathrm{En}_{0}\right)$. Other curves are our data for $\mathrm{En}_{99}$ and $\mathrm{En}_{1}$ samples converted to mass absorption coefficients scaled to match features in their data.

only substantial change in refractive index occurs at the surface of the diamonds, and its effect is mitigated by subtracting the spectrum of the empty cell from the data.

$\mathrm{KBr}$ - and polyethylene-pellet spectra of synthetic $\mathrm{MgSiO}_{3}$ (Oen) and $\mathrm{FeSiO}_{3}$ (Fs) orthopyroxenes obtained by Chihara et al., are compared with our $\mathrm{En}_{99}$ and $\mathrm{En}_{1}$ samples in Fig. 8. The peak wavelengths quoted by Chihara et al. are consistent with our data. However, there is a substantial difference in our derived mass absorption coefficients. Their mass absorption coefficients are factors of $6.0\left(\mathrm{En}_{99}\right)$ and 4.5 $\left(\mathrm{En}_{1}\right)$ weaker than ours in the $\mathrm{Si}-\mathrm{O}$ stretching and $\mathrm{Si}-\mathrm{O}-\mathrm{Si}$ bending regions $(8-17 \mu \mathrm{m})$ and in the far-IR beyond $\sim 40 \mu \mathrm{m}$, but the discrepancy in the $17-40 \mu \mathrm{m}$ range for $E_{99}$ is a factor of 3.0 and 3.4. Some large individual bands are much sharper than ours which is possibly an effect of the DAC spectra not fully sampling the $c$-axis due to the lath-like pyroxenes lying on their sides when crushed. These discrepancies occur because infrared spectra depend on the distance photons travel between grain-scattering and absorption events but the scattering measurement is complicated by the close correlation of absorption and reflection when the bands are strong. For this reason, different size grains are sampled by light transmitted by different motions within the crystal. DAC and diamond-compressioncell (DCC) measurements (see Section 7.2, below) reduce the effect of scattering because abutted grains have very similar refraction indices so that the reflection at grain boundaries is minimized and the absence of scattering enhances the observed mass absorption coefficients.

We also suspect that some of the Chihara et al. spectra contain small proportions of quartz $\left(\mathrm{SiO}_{2}\right)$ in addition to the olivine they identified because their data show peaks at 12.5 and $14.4 \mu \mathrm{m}$ and enhanced absorption at $9.2 \mu \mathrm{m}$. The effect of these impurities could be subtracted by the method used in Appendix A1. None of these issues invalidate their conclusions and their Oen and Fe spectra contain resolved peaks longward of 50 and $70 \mu \mathrm{m}$, respectively, when ours do not. 
7.2 Comparison with room temperature spectra of meteoritic grains

Meteoritic spectra were obtained by crushing individual micrometresized grains in a DCC (Bowey et al. 2007); $\mathrm{En}_{98-100}$ is normalized average of 13 grains, En $90-92$ is the average spectrum of three grains. These spectra are not wavelength shifted in comparison with our spectra and the fitted compositional trends are similar (see Fig. 5); where fits are different this is due to the much smaller compositional range covered by the meteoritic sample. Spectra of individual meteoritic grains have a much higher contrast in the strongest $\mathrm{Si}-\mathrm{O}$ stretches than do the DAC spectra. Due to this higher contrast and the narrowness of the features in the tiny samples one or two extra, very weak, bands were observed in some of the meteoritic spectra.

\subsection{Comparison with room- and low-temperature spectra}

Both continuum, and spectral measurements of dust and ice indicate that the ambient temperature of dust in many astronomical environments (e.g. planetary nebulae, molecular clouds and the discs of YSOs) is much colder $(\sim 10-200 \mathrm{~K})$ than the room temperature spectra obtained in most laboratory experiments. In order to explore the effect of temperature on the 17-85 $\mu \mathrm{m}$ spectra of crystalline olivines and pyroxenes Bowey et al. (2001) obtained measurements of powdered samples mixed with petroleum jelly on 0.8 -mm-thick polyethylene substrates at room- and low-temperature $(\sim 3.5 \mathrm{~K})$. They found that $3.5-\mathrm{K}$ peaks occurred at shorter wavelengths than do the corresponding $295-\mathrm{K}$ peaks. In order to compare temperaturerelated wavelength shifts and compositional wavelength shifts their data for pyroxenes are compared with our new spectra in Fig. 9. As expected, wavelengths of bands and band shapes of their roomtemperature spectra are consistent with our DAC spectra of samples from the same locality (i.e. samples with near identical compositions): our spectrum of $\mathrm{En}_{85}$ matches their spectrum of Bamble enstatite, as do $\mathrm{Wo}_{50} \mathrm{En}_{47}$ and the Bowey et al. (2001) diopside. However, the peak wavelengths of bands $o T_{6 E}$ and $o T_{4}$ in the $3.5 \mathrm{~K}$ spectra are best matched by our room-temperature $\mathrm{En}_{99}$ spectrum and $o T_{5}$ is best matched by En ${ }_{92}$ even though the low-temperature sample is $\mathrm{En}_{85}$. If the low-temperature data were from an astronomical source, the conclusion could be that the enstatite is of near endmember, $\mathrm{En}_{100}$, composition, that is it is $7-15$ per cent richer in $\mathrm{Mg}$ than it really is, or that there are two minerals contributing, En ${ }_{92}$ and $\mathrm{En}_{99}$ when only $\mathrm{En}_{85}$ is present.

There is less scope for temperature shifts to masquerade as compositional shifts in the diopside spectra because bands $h T_{2}, w T_{3}$, and $h T_{3}$ only appear separately in near end-member diopsides in the $\mathrm{Dp}-\mathrm{Hd}$ series and the temperature shifts are 10 times greater $(0.1-$ $0.3 \mu \mathrm{m}$ ) than the available compositional shifts and $c T$ is broader in the non-end-member clinopyroxenes. The longest wavelength band $h T_{4}$ is probably too broad and inspecific to pyroxenes to be useful for temperature studies; differences between the room-temperature spectra of this mineral are probably due to uncorrected fringes.

Low-temperature measurements of a wider variety of pyroxenes are needed to properly quantify these effects, but the incorrect inferred compositional differences between our room- and lowtemperature laboratory spectra suggest that Mg-end-member astronomical enstatites identified in far-IR astronomical spectra might not really be of end-member composition. A lower $\mathrm{Mg}$ :Fe ratio in the astronomical dust would be more consistent with the ratios measured in the meteoritic enstatites sampled by Bowey et al. (2007).
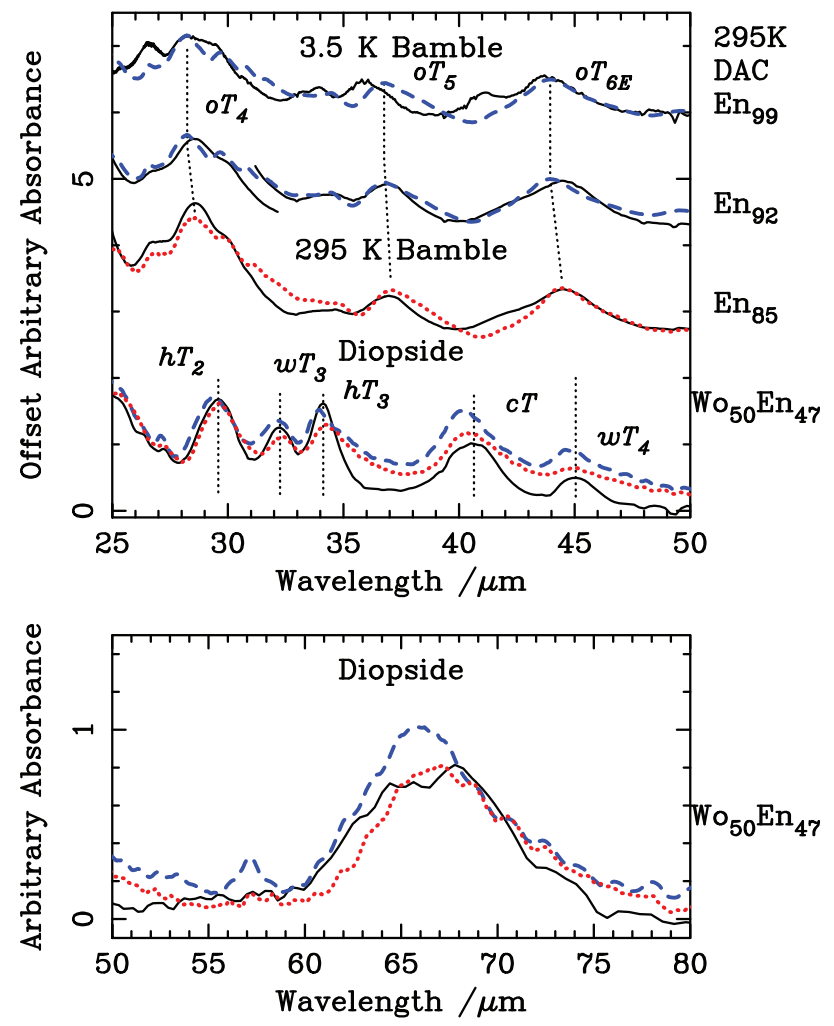

Figure 9. Comparison between room temperature DAC enstatite and $\mathrm{Wo}_{50} \mathrm{En}_{47}$ spectra (solid) and Bamble Enstatite and Diopside room temperature (red dotted) and low temperature spectra (blue dashed) from Bowey et al. (2001). The matching DAC spectrum is indicated to the right of each spectrum. The difference in wavelength between room-temperature spectra of minerals of identical composition obtained by the two methods is insignificant within the uncertainties. However, the low temperature spectrum of $\mathrm{En}_{85}$ is blueshifted with respect to the room temperature spectrum making it appear that the cold sample has the composition of room temperature En 99 (bands $o T_{6 E}$ and $\left.o T_{4}\right)$, or $\operatorname{En}_{92}\left(o T_{5}\right)$, that is it is 7-15 per cent more Mg-rich than its known composition.

\section{SUMMARY}

We present quantitative $8-90-\mu \mathrm{m}$ spectra of $8 \mathrm{Mg}$ - and Fe-bearing orthopyroxenes, $9 \mathrm{Mg}$-, Ca-, and Fe-bearing clinopyroxenes and one Ca-bearing pyroxenoid obtained at room temperature. Spectra were obtained from thin films of finely ground minerals crushed in a DAC without the use of an embedding medium. Pyroxenes have rich infrared spectra with many narrow peaks. In general, the wavelengths of the peaks increase as $\mathrm{Mg}$ is replaced in the lattice by $\mathrm{Ca}$ or $\mathrm{Fe}$. However, two bands in the En-Fs (orthopyroxene) series shift to shorter wavelengths as the Fe component increases from 0 percent to 60 percent. The most prominent band to do so is at $11.6 \mu \mathrm{m}$ when $\mathrm{Mg} \sim 99$ per cent and $11.2 \mu \mathrm{m}$ when $\mathrm{Mg} \lesssim 40$ per cent; below $\mathrm{En}_{40}$ the band is more prominent and does not shift further with an increase in Fe. This $11.2 \mu \mathrm{m}$ feature resembles an astronomical emission or absorption feature which is normally associated with olivines, forsterite or occasionally PAH absorption.

Only two bands are common to all the pyroxenes studied: an $\mathrm{Si}-\mathrm{O}$ stretching mode at $10.22 \mu \mathrm{m}$ in $\mathrm{En}_{99}$ and an $\mathrm{Si}-\mathrm{O}-\mathrm{Si}$-bending mode at $15.34 \mu \mathrm{m}$ in $\mathrm{En}_{99}$. We suggest that $\mathrm{Si}-\mathrm{O}-\mathrm{Si}$ bending modes between 13 and $16 \mu \mathrm{m}$ hold promise for the identification of chain silicates in MIRI spectra obtained with the JWST, because the pyroxene pattern is distinct in this range. 
The new spectra are compared with published 8-17 $\mu \mathrm{m}$ roomtemperature transmission spectra of meteoritic pyroxenes and $\mathrm{KBr}$ and polyethylene-pellet spectra of terrestrial pyroxenes. The ratios between strong and weak peaks change as does the spectral contrast, but the $10-\mu \mathrm{m}$ features are not wavelength shifted provided the minerals have the same chemical composition and crystal structure. However, because scattering between grain boundaries is reduced in DAC measurements of compressed powders, mass absorption coefficients in our data are up to six times the values measured in $\mathrm{KBr}$ and polyethylene pellets.

Room-temperature data from a Bowey et al. (2001) 17-85 $\mu \mathrm{m}$ study of two of our samples embedded in petroleum jelly on polyethylene substrates have band shapes, wavelengths, and relativeband strengths which are consistent with our DAC spectra. However, comparison of their low-temperature spectra with our roomtemperature data indicates that the spectroscopically identified ' $\mathrm{Mg}$ end-member' grains in $10 \mathrm{~K}$ astronomical dust might contain 815 per cent $\mathrm{Fe}$ due to temperature-related wavelength shifts to the blue at low temperatures masquerading as compositional shifts in peak wavelength. Low- and intermediate-temperature far-IR measurements of a wider variety of pyroxenes and other silicates are needed to quantify these effects.

Our data contain a wide variety of spectral features between 40 and $80 \mu \mathrm{m}$ which could be used to diagnose both the mineralogy, and the temperatures of specific grain populations if new observations with a far-infrared spectrometer on the proposed Space Infrared Telescope for Cosmology and Astrophysics were to be obtained. Such a study would provide a substantive link between the silicates mineralogists and meteoriticists analyse in the laboratory and the mineralogy inferred from astronomical observations.

\section{ACKNOWLEDGEMENTS}

JEB is supported by a two-year Ernest Rutherford Returner Fellowship (ST/S004106/1) funded by the UK's Science and Technology Facilities Council. The measurements at WU by EK and AMH were supported by the USA National Science Foundation (grant AST-9805924) and the USA National Aeronautics and Space Administration grant (APRA04-000-0041). We thank Dan Kremser of Washington University for the microprobe analyses, P. G. Woodcraft for his patience during the Covid-19 lockdown, those who have aided JEB's return to research after a 13.5 year career break, and the anonymous referee for careful reviews.

\section{DATA AVAILABILITY}

The pyroxene spectra presented this article are subject to restricted access for 12 months from the publication date of the article during which data will be available from the authors and doi on request. Afterwards the data will be freely available from the doi and group https://zenodo.org/communities/mineralspectra/

\section{REFERENCES}

Armstrong J., 1988, in Newbury D. E., ed., Microbeam Analysis. San Francisco Press, San Francisco, p. 469

Bohren C. F., Huffman D. R., 1983, Absorption, Scattering of Light by Small Particles. Wiley, New York

Bowey J. E., Adamson A. J., 2002, MNRAS, 334, 94
Bowey J. E., Hofmeister A. M., 2005, MNRAS, 358, 1383

Bowey J. E., Adamson A. J., Speck A. K., 2000, in Sitko M. L., Sprague A. L., Lynch D. K., eds, ASP Conf. Ser. Vol. 196, Thermal Emission Spectroscopy and Analysis of Dust, Disks, and Regoliths, Astron. Soc. Pac., San Francisco, p. 31

Bowey J. E., Lee C., Tucker C., Hofmeister A. M., Ade P. A. R., Barlow M. J., 2001, MNRAS, 325, 886

Bowey J. E., Morlok A., Köhler M., Grady M., 2007, MNRAS, 376, 1367

Bregman J. D., Hayward T. L., Sloan G. C., 2000, ApJ, 544, 75

Chen R., Luo A., Liu J., Jiang B., 2016, AJ, 151, 146.

Chihara H., Koike C., Tsuchiyama A., Tachibana S., Sakamoto D., 2002, A\&A, 391, 267

Deer W. A., Howie R. A., Zussman J., 1978, Rock-Forming Minerals, Vol. 2A: Single Chain Silicates, 2nd edn. Longman, London

Do-Duy T., Wright C. M., Fujiyoshi T., Glasse A., Siebenmorgen R., Smith R., Stecklum B., Sterzik M., 2020, MNRAS, 493, 4463

Ferraro J. R., 1982, The Sadtler Infrared Spectra Handbook of Minerals and Clays. Sadtler Research Laboratories, Philadelphia

Goldman D. S., Rossman G. R., 1979, Phys. Chem. Mineral, 4, 43

Griffiths P. R., de Haseth J. A., 1986, Fourier Transform Infrared Spectrometry. John Wiley Sons, New York

Hanner M. S., Lynch D. K., Russell R. W., 1994, ApJ, 425, 274

Hemingway B. S., Bohlen S. R., Hankins W. B., Westrum E. F., Kuskov O. L., 1998, Am. Mineral, 83, 409

Hofmeister A. M., 2012, Eur. J. Mineral., 24, 669

Hofmeister A. M., Bowey J. E., 2006, MNRAS, 367, 577

Hofmeister A. M., Pertermann M., 2008, Eur. J. Mineral, 20, 537

Hofmeister A. M., Pitman K., 2007, Phys. Chem. Mineral., 34, 319

Hofmeister A. M., Xu J., Mao H.-K., Bell P. M., Hoering T. C., 1989, Am. Mineral, 74, 281

Hofmeister A. M., Keppel E., Speck A. K., 2003, MNRAS, 345, 16

Huebner J. S., Turnock A. C., 1980, Am. Min, 65, 225

Imai Y., Koike C., Chihara H., Murata K., Aoki T., Tsuchiyama A., 2009, A\&A, 507, 277

Jaeger C., Molster F. J., Dorschner J., Henning Th., Mutschke H., Waters L. B. F. M., 1998, A\&A, 339, 904

Johnson N. M., 2002, PhD thesis, Washington University in St. Louis, Missouri, USA

Johnson N. M., Fegley B., 2003, Icarus, 164, 317

Koike C., Noguchi R., Chihara H., Suto H., Ohtaka O., Imai Y., Matsumoto T., Tsuchiyama A., 2013, ApJ, 778, 60

Malfait K., Waelkens C., Waters L. B. F. M., Vandenbussche B., Huygen E., de Graauw M. S., 1998, A\&A, 332, L25

Morimoto N. et al., 1988, Am. Mineral, 73, 1123

Okada A., Keil K., Taylor G. J., Newsom H., 1988, Metic, 23, 59

Ormaasen D. E., 1977, Lithos, 10, 291

Pitman K. M., Dijkstra C., Hofmeister A. M., Speck A. K., 2010, MNRAS, 406,460

Sogawa H., Koike C., Chihara H., Suto H., Tachibana S., Tsuchiyama A., Kozasa T., 2006, A\&A, 451, 357

Speck A. K., Hofmeister A. M., Barlow M. J., 1999, ApJ, 513, 87

Speck A. K., Wittington A. G., Hofmeister A. M., 2011, ApJ, 740, 93

Spoon H. W. W. et al., 2006, ApJ, 638, 759

Tamanai A., Mutschke H., Blum J., 2009, in Henning Th., Grün E., Steinacker J., eds, ASP Conf Ser. Vol. 414, Cosmic Dust- Near and Far. Astron. Soc. Pac., San Francisco, p. 438

Waters L. B. F. M. et al., 1996, A\&A, 315, L361

Willett K. W., Darling J., Spoon H. W. W., Charmandaris V., Armus L., 2011, ApJS, 193, 18

Wooden D. H., Harker D. E., Woodward C. E., Butner H. M., Koike C., Witteborn F. C., McMurtry C. W., 1999, ApJ, 517, 1034

Wooten F., 1972, Optical Properties of Solids. Academic Press, San Diego, CA 


\section{APPENDIX A: ESTIMATED FILM THICKNESSES, MERGING POINTS, AND QUARTZ CORRECTION}

\section{A1 Quartz correction in $\mathbf{E n}_{12}$ and $\mathbf{E n}_{1}$}

The spectrum of $\mathrm{En}_{1}$, the ferrosilite, Fe-end-member orthopyroxene has weak bands at 12.50 and $12.82 \mu \mathrm{m}$ (which are very weak in $\mathrm{En}_{12}$ ) in addition to a very weak $14.37 \mu \mathrm{m}$ band. These bands match the wavelengths of bands in $\alpha$ quartz (see Koike et al. 2013). Therefore we obtained a DAC spectrum of quartz, scaled it to the 12.5- and 12.8$\mu \mathrm{m}$ features, and subtracted it from our mid-IR data (Fig. A1). These data were merged with the re-scaled far-IR spectra before the band strength calibration. Quartz bands were not detected or subtracted from the far-IR spectra.

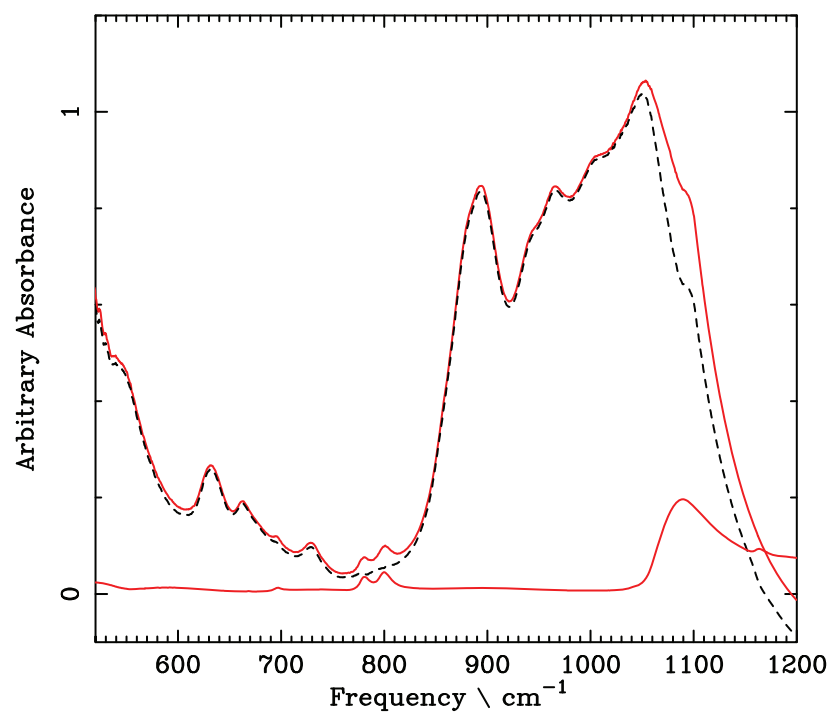

Figure A1. Removal of quartz impurity from $\mathrm{En}_{1}$ spectrum. A quartz spectrum, scaled to bands at 12.5 and $12.82 \mu \mathrm{m}$ (bottom solid red curve), was subtracted from the mid-IR range of $\mathrm{En}_{1}$ (black dashed line). The cleaned $\mathrm{En}_{1}$ spectrum is the main solid red curve.
Table A1. Mid-IR (450-4000 $\mathrm{cm}^{-1}$ spectra were defringed and merged with scaled far-IR $\left(80-650 \mathrm{~cm}^{-1}\right)$ spectra at point $\mathrm{P} 1$. In both cases, the separation between data points is about $0.5 \mathrm{~cm}^{-1}$, unless otherwise specified. The 1$2 \mathrm{~cm}^{-1}$ resolution specified in Section 3 describes how close peaks can lie but still be distinguished. In some spectra reflection artificially broadened the $\mathrm{Si}-\mathrm{O}$ stretch near $1100 \mathrm{~cm}^{-1}$ : this was subtracted by fitting a curve to the unaffected spectrum of $\mathrm{En}_{55}$ and scaling this to the affected spectra at P2. The position of $\mathrm{P} 2$ was chosen so that real kinks in the data were not removed.

\begin{tabular}{|c|c|c|c|}
\hline Sample & $\begin{array}{c}d(\mathrm{MIR}) \\
\mu \mathrm{m}\end{array}$ & $\begin{array}{c}\mathrm{P} 1 \\
\mathrm{~cm}^{-1}(\mu \mathrm{m})\end{array}$ & $\begin{array}{c}\mathrm{P} 2 \\
\mathrm{~cm}^{-1}(\mu \mathrm{m})\end{array}$ \\
\hline$E_{99}$ & 0.25 & $582(17.2)$ & $1156(8.6)$ \\
\hline $\mathrm{En}_{92}$ & 0.29 & $546(18.3)$ & $1150(8.7)$ \\
\hline$E_{90}$ & 0.38 & $595(16.8)$ & - \\
\hline $\mathrm{En}_{85}$ & 0.86 & $519(19.3)$ & $-^{a}$ \\
\hline $\mathrm{Wo}_{10} \mathrm{En}_{62}$ & 0.87 & $484(20.7)$ & - \\
\hline $\mathrm{En}_{55}$ & 0.35 & $486(20.6)$ & - \\
\hline $\mathrm{En}_{40}$ & 0.25 & $584(17.1)$ & $1116(9.0)$ \\
\hline $\mathrm{En}_{12}$ & 0.44 & $471(21.2)$ & $1103(9.1)$ \\
\hline $\mathrm{En}_{1}$ & 0.65 & $520(19.2)$ & $1102(9.1)$ \\
\hline $\mathrm{Wo}_{21} \mathrm{En}_{79}$ & 0.78 & $482(20.7)$ & $1135(8.8)$ \\
\hline $\mathrm{Wo}_{30} \mathrm{En}_{70}$ & 0.53 & $469(21.3)$ & $1131(8.8)$ \\
\hline $\mathrm{Wo}_{40} \mathrm{En}_{60}$ & 0.48 & $527(19.0)^{b}$ & $1131(8.8)$ \\
\hline $\mathrm{Wo}_{50} \mathrm{En}_{50}$ & 0.71 & $458(21.8)$ & $1136(8.8)$ \\
\hline $\mathrm{Wo}_{50} \mathrm{En}_{47}$ & 0.19 & $490(20.4)^{c}$ & 1144 (8.7) \\
\hline $\mathrm{Wo}_{49} \mathrm{En}_{36}$ & 1.01 & $454(22.0)$ & - \\
\hline $\mathrm{Wo}_{36} \mathrm{En}_{37}$ & 0.46 & $442(22.6)$ & - \\
\hline $\mathrm{Wo}_{47} \mathrm{En}_{6}$ & 0.38 & $557(18.0)$ & - \\
\hline $\mathrm{Wo}_{99} \mathrm{En}_{1}$ & 0.88 & $451(22.2)$ & - \\
\hline
\end{tabular}

Notes: ${ }^{a}$ Defringing was not required; MIR resolution was $1 \mathrm{~cm}^{-1}$ and FIR $0.5 \mathrm{~cm}^{-1}$.

${ }^{b}$ Data between 508 and $528(18.9-19.7 \mu \mathrm{m})$ were interpolated due to difficulties with the merge; structure here is spurious.

${ }^{c}$ MIR spectral resolution was $1.0 \mathrm{~cm}^{-1}$ and FIR: $0.5 \mathrm{~cm}^{-1}$.

Table A2. Mineral compositions for samples microprobed at Washington University.

\begin{tabular}{lccc}
\hline $\begin{array}{l}\text { Sample } \\
\text { Locality }\end{array}$ & $\begin{array}{c}\mathrm{Wo}_{49} \mathrm{En}_{36} \\
\text { Calumet }\end{array}$ & $\begin{array}{c}\mathrm{Wo}_{47} \mathrm{En}_{6} \\
\text { Iona Is. }\end{array}$ & $\begin{array}{c}\mathrm{Wo}_{36} \mathrm{En}_{37} \\
\text { Belmont }\end{array}$ \\
\hline Oxide/percent & 51.57 & 48 & 49.95 \\
$\mathrm{SiO}_{2}$ & 0.16 & - & 0.85 \\
$\mathrm{TiO}_{2}$ & 1.45 & 0.5 & 1.83 \\
$\mathrm{Al}_{2} \mathrm{O}_{3}$ & - & - & 0.01 \\
$\mathrm{Cr}_{2} \mathrm{O}_{3}$ & - & 2 & - \\
$\mathrm{Fe}_{2} \mathrm{O}_{3}$ & 7.79 & 23 & 14.93 \\
$\mathrm{FeO}$ & 0.52 & 1 & 0.36 \\
$\mathrm{MnO}$ & 13.03 & 2 & 13.06 \\
$\mathrm{MgO}$ & 24.55 & 21 & 17.43 \\
$\mathrm{CaO}$ & 0.11 & - & 0.25 \\
$\mathrm{Na}{ }_{2} \mathrm{O}$ & - & - & - \\
$\mathrm{K}_{2} \mathrm{O}$ & - & - & - \\
$\mathrm{H}_{2} \mathrm{O}^{+}$ & - & - & - \\
$\mathrm{H}_{2} \mathrm{O}^{-}$ & & & \\
$\mathrm{Impurities}$ & 99.18 & 97.5 & 98.67 \\
$\mathrm{Total}^{-}$ & & & \\
\hline
\end{tabular}

This paper has been typeset from a $\mathrm{T}_{\mathrm{E}} \mathrm{X} / \mathrm{L} \mathrm{T} \mathrm{T}_{\mathrm{E}} \mathrm{X}$ file prepared by the author. 